TITLE:

\title{
Influence of heat input waveform on transient critical heat flux of subcooled water flow boiling in a short vertical tube
}

\section{AUTHOR(S):}

Hata, Koichi; Masuzaki, s.

\section{CITATION:}

Hata, Koichi ... [et al]. Influence of heat input waveform on transient critical heat flux of subcooled water flow boiling in a short vertical tube. Nuclear Engineering and Design 2010, 240(2): 440-452

ISSUE DATE:

2010-02

URL:

http://hdl.handle.net/2433/91253

\section{RIGHT:}

c 2008 Elsevier B.V. All rights reserved.; この論文は出版社版でありませ ん。引用の際には出版社版をご確認ご利用ください。; This is not the published version. Please cite only the published version. 


\title{
INFLUENCE OF HEAT INPUT WAVEFORM ON TRANSIENT CRITICAL HEAT FLUX OF SUBCOOLED WATER FLOW BOILING IN A SHORT VERTICAL TUBE
}

\author{
Hata $\mathbf{K}^{*}$ \\ Institute of Advanced Energy \\ Kyoto University \\ Gokasho, Uji, Kyoto 611-0011, Japan \\ hata@,iae.kyoto-u.ac.jp
}

\section{Masuzaki S}

National Institute for Fusion Science

322-6 Oroshi-cho, Toki, Gifu 509-5292, Japan

masuzaki.suguru@lhd.nifs.ac.jp

\begin{abstract}
The transient critical heat fluxes (CHFs) of the subcooled water flow boiling for ramp-wise heat input $\left[Q=\alpha t, \alpha=6.21 \times 10^{8}\right.$ to $1.63 \times 10^{12} \mathrm{~W} / \mathrm{m}^{3} \mathrm{~s},\left(q \cong 1.08 \times 10^{7}\right.$ to $\left.\left.6.00 \times 10^{7} \mathrm{~W} / \mathrm{m}^{2}\right)\right]$ and stepwise one [ $Q=Q_{s}, Q_{s}=0 \mathrm{~W} / \mathrm{m}^{3}$ at $t=0 \mathrm{~s}$ and $Q_{s}=2.95 \times 10^{10}$ to $7.67 \times 10^{10} \mathrm{~W} / \mathrm{m}^{3}$ at $t>0 \mathrm{~s},\left(q=0 \mathrm{~W} / \mathrm{m}^{2}\right.$ at $t=0$ $\mathrm{s}$ and $q \cong 1.61 \times 10^{7}$ to $3.87 \times 10^{7} \mathrm{~W} / \mathrm{m}^{2}$ at $\left.\left.t>0 \mathrm{~s}\right)\right]$ with the flow velocities $(u=4.0$ to $13.3 \mathrm{~m} / \mathrm{s})$, the
\end{abstract}

${ }^{*}$ Corresponding author 
inlet subcoolings $\left(\Delta T_{\text {sub,in }}=86.8\right.$ to $\left.153.3 \mathrm{~K}\right)$ and the inlet pressures $\left(P_{i n}=742.2\right.$ to $\left.1293.4 \mathrm{kPa}\right)$ are systematically measured by an experimental water loop comprised of a pressurizer. The SUS304 tubes of inner diameters $(d=3,6$ and $9 \mathrm{~mm})$, heated lengths $(L=33.15,59.5$ and $49.3 \mathrm{~mm}), L / d$ $(=11.05,9.92$ and 5.48$)$, and wall thickness $(\delta=0.5,0.5$ and $0.3 \mathrm{~mm})$ respectively with the rough finished inner surface (Surface roughness, $R a=3.18 \mu \mathrm{m}$ ) are used in this work. The experimental errors in the subcooling measure and the pressure one are $\pm 1 \mathrm{~K}$ and $\pm 1 \mathrm{kPa}$, while in the heat flux it is $\pm 2 \%$. The transient CHF data for the ramp-wise heat input and the stepwise one are compared with those for the exponentially increasing heat input $\left(Q=Q_{0} \exp (t / \tau), \tau=16.82 \mathrm{~ms}\right.$ to 15.52 s) previously obtained and the dominant variables on transient CHF for heat input waveform difference are confirmed. The transient CHF data are compared with the values calculated by the steady state CHF correlations against inlet and outlet subcoolings, and the applicability of steady state CHF correlations is confirmed extending its possible validity for the reduced time, $\omega_{p}$, down to $800 \mathrm{~ms}$. The transient CHF data are compared with the values calculated by the transient CHF correlations against inlet and outlet subcoolings, and the influence of heat input waveform on transient CHF is clarified based on the experimental data for the ramp-wise heat input, the stepwise one and the exponentially increasing one. The dominant mechanisms of the subcooled flow boiling critical heat flux for the ramp-wise heat input, the stepwise one and the exponentially increasing one are discussed.

\section{KEYWORDS}

Transient Critical Heat Flux, Subcooled Water Flow Boiling, Ramp-wise Heat Input, Stepwise Heat Input, Exponentially Increasing Heat Input, Short Vertical Tube 


\section{INTRODUCTION}

The influence of heat input waveform on transient critical heat flux (CHF) of subcooled water flow boiling is necessary for investigating the mechanism of CHF, especially in relation to study of the reliability of a divertor in a nuclear fusion facility. The nuclear fusion facility has two operation modes. One is the steady-state operation mode, and the other one is the transient one. The plasma facing material in transient operation mode is exposed to a heat load three times longer or more than during steady-state operation for several seconds. The knowledge of transient high heat flux heat removal with various plasma waveform becomes very important to take the heat out of the plasma facing material.

Many researchers have experimentally studied the steady state CHF in forced convective boiling uniformly heated on the test tube by a steadily increasing current [1-7]. The transient CHF experiments on forced convective boiling were conducted to a platinum wire in water flowing upward by Kataoka et al. [8] and to a circular vertical tube using refrigerant-12 as the working fluid by Celata et al. [9-11]. We have already measured the steady state CHFs, $q_{c r, s u b, s t}$, (2351 points) of the subcooled water flow boiling with SUS304, Cupro Nickel and Platinum test tubes for wide ranges of test tube inner diameters ( $d=2$ to $12 \mathrm{~mm}$ ), heated lengths ( $L=22$ to $149.7 \mathrm{~mm}$ ), $L / d$ ( $=4.08$ to 74.85$)$, outlet pressures $\left(P_{\text {out }}=159 \mathrm{kPa}\right.$ to $\left.1 \mathrm{MPa}\right)$, flow velocities $(u=4.0$ to 13.3 $\mathrm{m} / \mathrm{s})$, dissolved oxygen concentrations $\left(\mathrm{O}_{2}=8.63\right.$ to $\left.0.0265 \mathrm{ppm}\right)$ and surface roughness $(R a=3.18$ to $0.14 \mu \mathrm{m})$ to establish the database for designing the divertor of a helical type fusion 
experimental device, which is a Large Helical Device (LHD) located in the National Institute for Fusion Science, Japan [12-21]. We have given the steady state CHF correlations against inlet subcooling, Eq. (1), and outlet subcooling, Eq. (2), based on the effects of test tube inner diameter $(d)$, flow velocity $(u)$, inlet and outlet subcoolings $\left(\Delta T_{\text {sub,in }}\right.$ and $\left.\Delta T_{\text {sub,out }}\right)$ and ratio of heated length to inner diameter $(L / d)$ on CHF.

$$
\begin{aligned}
B o=C_{1} D^{*-0.1} W e^{-0.3}\left(\frac{L}{d}\right)^{-0.1} e^{-\frac{(L / d)}{C_{2} R e^{0.4}}} S c^{* C_{3}} \\
\text { if inlet subcooling is known }\left(\Delta T_{\text {sub,in } \geq 40 \mathrm{~K})}\right. \\
\text { Bo }=0.082 D^{*-0.1} W^{-0.3}\left(\frac{L}{d}\right)^{-0.1} S c^{0.7}
\end{aligned}
$$

if outlet subcooling is known $\left(\Delta T_{\text {sub,out }} \geq 30 \mathrm{~K}\right)$

where $C_{1}=0.082, C_{2}=0.53$ and $C_{3}=0.7$ for $L / d \leq$ around 40 and $C_{l}=0.092, C_{2}=0.85$ and $C_{3}=0.9$ for $L / d>$ around $40 . B o, D^{*}, W e, S c^{*}$ and $S c$ are boiling number $\left(B o=q_{c r, s u b} / G h_{f g}\right)$, non-dimensional diameter $\quad\left[D^{*}=d /\left\{\sigma / g /\left(\rho_{l}-\rho_{g}\right)\right\}^{0.5}\right]$, Weber number $\left(W e=G^{2} d / \rho_{l} \sigma\right)$, non-dimensional inlet subcooling $\left(S c^{*}=c_{p l} \Delta T_{s u b, i n} / h_{f g}\right)$ and non-dimensional outlet subcooling $\left(S c=c_{p l} \Delta T_{s u b, o u t} / h_{f g}\right)$ respectively. Saturated thermo-physical properties were evaluated at the outlet pressure.

The steady state CHF correlations against inlet subcooling, Eq. (1), and outlet subcooling, Eq. (2), can describe the authors' published steady state CHF data (2351 points) within $15 \%$ difference for inlet subcoolings $\left(\Delta T_{\text {sub, in }}=40\right.$ to $\left.155 \mathrm{~K}\right)$ and outlet subcoolings ( $\Delta T_{\text {sub, out }}=30$ to 140 $\mathrm{K})$ on test tubes with rough, smooth and mirror finished inner surfaces, although the CHF data 
(32 points) with the mirror finished inner surface $(R a=0.14 \mu \mathrm{m})$ are distributed within -30 to $+7.6 \%$ difference of Eq. (2) for $71.4 \mathrm{~K} \leq \Delta T_{\text {sub,out }} \leq 108.4 \mathrm{~K}$.

Furthermore, we have already measured the transient CHFs, $q_{c r, s u b}$, (473 points) for the exponentially increasing heat input with a wide range of exponential periods, $\tau,\left(Q=Q_{0} \exp (t / \tau)\right.$, $\tau=16.82 \mathrm{~ms}$ to $15.52 \mathrm{~s}$ ). It has been clarified that the ratios of the difference between the transient CHFs and the steady state ones to the steady state ones, $\left(q_{c r, s u b}-q_{c r, s u b, s t}\right) / q_{c r, s u b, s t}$, are almost proportional to $\tau^{-0.6}$ for fixed $\Delta T_{s u b, i n}$ and $u$. These data can be expressed by the empirical correlation.

$$
\frac{q_{c r, s u b}-q_{c r, s u b, s t}}{q_{c r, s u b, s t}}=11.4 p^{*-0.6}
$$

where $p^{*}$ is the non-dimensional exponential period, $p^{*}=\tau u /\left\{\sigma / g /\left(\rho_{l^{-}} \rho_{g}\right)\right\}^{0.5}$. We have given the following transient CHF correlations against inlet subcooling, Eq. (4), and outlet subcooling, Eq. (5), on the basis of the effect of the non-dimensional exponential period for the inner diameters of 3, 6, 9 and $12 \mathrm{~mm}$ and the heated lengths of 33.15 to $132.9 \mathrm{~mm}$ with $L / d=5.48$ to 11.075 at the outlet pressures of around 800 and $1100 \mathrm{kPa}[22-25]$.

$$
B o=C_{1} D^{*-0.1} W e^{-0.3}\left(\frac{L}{d}\right)^{-0.1} e^{-\frac{(L / d)}{C_{2} R e^{0.4}}} S c^{* C_{3}} \times\left(1+11.4 p^{*-0.6}\right)
$$

if inlet subcooling is known $\left(\Delta T_{\text {sub,in }} \geq 40 \mathrm{~K}\right)$ 


$$
B o=0.082 D *^{-0.1} W e^{-0.3}\left(\frac{L}{d}\right)^{-0.1} S c^{0.7} \times\left(1+6.34 p^{*-0.6}\right)
$$

if outlet subcooling is known $\left(\Delta T_{\text {sub,out }} \geq 30 \mathrm{~K}\right)$

Most of the data (473 points) are within $15 \%$ difference of Eqs. (4) and (5) for wide exponential period.

The objectives of present study are sixfold. First is to measure the transient CHFs for ramp-wise heat input with various coefficients of ramp heat input and for stepwise heat input with various step heights of heat input. Second is to compare those with the transient CHF data for the exponentially increasing heat input previously obtained. Third is to clarify dominant variables on transient CHF for heat input waveform difference. Fourth is to confirm the applicability of transient CHF correlations against inlet subcooling, Eq. (4), and outlet subcooling, Eq. (5), based on the experimental data for the exponentially increasing heat input. Fifth is to derive the transient CHF correlations against inlet and outlet subcoolings for various heat input waveforms. Sixth is to discuss the mechanisms of the subcooled flow boiling critical heat flux in a short vertical tube.

\section{EXPERIMENTAL APPARATUS AND METHOD}

\subsection{Experimental Water Loop}

The schematic diagram of experimental water loop comprised of the pressurizer is shown in Fig.

1. The loop is made of SUS304 stainless steel and is capable of working up to $2 \mathrm{MPa}$. The loop 
has five test sections whose inner diameters are 2, 3, 6, 9 and $12 \mathrm{~mm}$. Test sections were vertically oriented with water flowing upward. The three test sections of the inner diameters of 3 , 6 and $9 \mathrm{~mm}$ were used in this work. The circulating water was distilled and deionized with about 5-M $\Omega \mathrm{cm}$ specific resistivity. The circulating water through the loop was heated or cooled to keep a desired inlet temperature by pre-heater or cooler. The flow velocity was measured by a mass flow meter using a vibration tube (Nitto Seiko, CLEANFLOW 63FS25, Flow range=100 and $750 \mathrm{Kg} / \mathrm{min}$ ). The flow velocity was controlled by regulating the frequency of the threephase alternating power source to the canned type circulation pump (Nikkiso Co., Ltd., Non-Seal Pump HT24B-B2, pump flow rate $=75 \mathrm{~m}^{3} / \mathrm{h}$, pump head=18 m). The water was pressurized by saturated vapor in the pressurizer in this work. The pressure at the inlet of the test tube was controlled within $\pm 1 \mathrm{kPa}$ of a desired value by using a heater controller of the pressurizer.

\subsection{Test Section}

The cross-sectional view of 3,6 and 9-mm inner diameter test sections used in this work is shown in Fig. 2. The SUS304 test tubes with 3 different surface roughness have been generally used. The test tubes with rough and smooth finished inner surfaces (RF and SF) are commercially available. The rough finished inner surface was fabricated by annealing the test tubes first in the atmosphere of air and was then acidized, while the smooth finished inner surface was fabricated by annealing the test tubes in the atmosphere of hydrogen gas. The smooth finished inner surface test tube was polished up to around $25 \mu \mathrm{m}$ deep by the electrolytic abrasive treatment to realize the mirror finished one (MF). The rough finished inner surface test tube (RF) was used in this work. Wall thickness of the test tubes, $\delta$, was 0.3 and $0.5 \mathrm{~mm}$. The 
inner surface condition of the test tube was observed by the scanning electron microscope (SEM) photograph and inner surface roughness was measured by Tokyo Seimitsu Co., Ltd.'s surface texture measuring instrument (SURFCOM 120A). Figure 3 shows the SEM photograph of the test tube with the rough finished inner surface (RF). The inner surface roughness is measured $3.18 \mu \mathrm{m}$ for $R a, 27.28 \mu \mathrm{m}$ for $R \max$ and $21.16 \mu \mathrm{m}$ for $R z$. The silver-coated 5-mm thickness copper-electrode-plates to supply heating current were soldered to the surfaces of the both ends of the test tube. The both ends of test tube were electrically isolated from the loop by Bakelite plates of 14-mm thickness. The test tube was also thermally insulated from atmosphere with a Bakelite block of $120 \mathrm{~mm}$ wide, $80 \mathrm{~mm}$ deep and $L \mathrm{~mm}$ high.

\subsection{Method of Heating Test Tube}

The test tube has been heated with a ramp-wise heat input, a stepwise one and an exponentially increasing one supplied from a direct current source (Takasago Ltd., NL035-500R, DC 35 V3000 A) through the two copper electrodes, as shown in Fig. 4. The common specifications of the direct current source are as follows. Constant-voltage (CV) mode regulation is $0.005 \%+3$ $\mathrm{mV}$ of full scale, $\mathrm{CV}$ mode ripple is $500 \mu \mathrm{V}$ r.m.s. or better and $\mathrm{CV}$ mode transient response time is less than $200 \mu \mathrm{sec}$ (Typical) against $5 \%$ to full range change of load. The transient CHFs, $q_{c r, s u b}$, were realized by the ramp-wise heat input, the stepwise one and the exponentially increasing one to the test tube. At the $\mathrm{CHF}$, the test tube average temperature rapidly increases. The current for the heat input to the test tube was automatically cut off when the measured average temperature increased up to the preset temperature, which was several tens of Kelvin 
higher than corresponding CHF surface temperature. This procedure avoided actual burnout of the test tube. Details of the preset temperature are shown in Appendix A. 1.

\subsection{Measurement of CHF, Temperature and Pressure for Test Tube}

The transient average temperature of the test tube, $\overline{\boldsymbol{T}}$, was measured with resistance thermometry participating as a branch of a double bridge circuit for the temperature measurement. The output voltages from the bridge circuit, $V_{T}$, together with the voltage drop across the two electrodes, $V_{R}$, and across a standard resistance, $V_{I}$, were amplified and then were sent via a $\mathrm{D} / \mathrm{A}$ converter to a digital computer. These voltages were simultaneously sampled at a constant interval ranging from $60 \mu$ s to $200 \mathrm{~ms}$. The average temperature of the test tube was calculated with the aid of previously calibrated resistance-temperature relation, $R_{T}=a\left(1+b \overline{\boldsymbol{T}}+c \overline{\boldsymbol{T}}^{2}\right)$. The heat generation rate in the test tube, $Q$, was calculated from the measured voltage differences between the potential taps of the test tube and the standard resistance, $V_{R}$ and $V_{I}$. The surface heat flux is the difference between the heat generation rate per unit surface area and the rate of change of energy storage in the test tube obtained from the faired average temperature versus time curve as follows:

$$
q(t)=\frac{V}{S}\left(Q(t)-\rho c \frac{d \bar{T}}{d t}\right)
$$

where $\rho, c, V$ and $S$ are the density, the specific heat, the volume and the inner surface area of the test tube, respectively. The inner surface temperature, $T_{s}$, was also obtained by solving the heat 
conduction equation in the test tube under the conditions of measured average temperature, $\overline{\boldsymbol{T}}$, and heat generation rate, $Q$, of the test tube.

In case of the 3,6 and 9-mm inner diameter test sections, before entering the test tube, the test water flows through the tube with the same inner diameter of the test tube to form the fully developed velocity profile. The entrance tube lengths, $L_{e}$, are given 240,333 and $333 \mathrm{~mm}$ ( $L_{e} / d=80,55.5$ and 37). The values of $L_{e} / d$ for $d=3$ to $9 \mathrm{~mm}$ in which the center line velocity reaches $99 \%$ of the maximum value for turbulence flow were obtained ranging from 9.8 to 21.9 by the correlation of Brodkey and Hershey [26] as follows:

$$
\frac{L_{e}}{d}=0.693 R e^{1 / 4}
$$

The inlet and outlet liquid temperatures were measured by 1-mm o.d., sheathed, K-type thermocouples (Nimblox, Sheath material: SUS316, Hot junction: Ground, Response time (63.2\%): $46.5 \mathrm{~ms}$ ) which are located at the centerline of the tube at the upper and lower stream points of 262 and $53 \mathrm{~mm}$ from the tube inlet and outlet points for the 3-mm inner diameter test section, and at those of 283 and $63 \mathrm{~mm}$ from those points for the 6 and 9-mm inner diameter ones. The inlet and outlet subcoolings were given by the saturation temperatures and the inlet and outlet liquid temperatures measured experimentally at CHF point as follows:

$$
\begin{aligned}
& \Delta T_{\text {sub, in }}=T_{\text {sat }}\left(P_{\text {in }}\right)-T_{\text {in }} \\
& \Delta T_{\text {sub,out }}=T_{\text {sat }}\left(P_{\text {out }}\right)-T_{\text {out }}
\end{aligned}
$$


Evaluation of the outlet subcooling for power transient experiment is shown in Appendix A. 2.

The inlet and outlet pressures were measured by the strain gauge transducers (Kyowa Electronic Instruments Co., LTD., PHS-20A, Natural frequency: approximately $30 \mathrm{kHz}$ ), which were located near the entrance of conduit at upper and lower stream points of $53 \mathrm{~mm}$ from the tube inlet and outlet points for $d=3 \mathrm{~mm}$ inner diameter test section, and at those of $63 \mathrm{~mm}$ from those points for $d=6$ and $9 \mathrm{~mm}$ inner diameter ones. The thermocouples and the transducers were installed in the conduits as shown in Fig. 2. The inlet and outlet pressures were calculated from the pressures measured by inlet and outlet pressure transducers as follows:

$$
\begin{aligned}
& \boldsymbol{P}_{i n}=\boldsymbol{P}_{i p t}-\left\{\left(\boldsymbol{P}_{i p t}\right)_{w n h}-\left(\boldsymbol{P}_{o p t}\right)_{w n h}\right\} \times \frac{\boldsymbol{L}_{i p t}}{\boldsymbol{L}_{i p t}+\boldsymbol{L}+\boldsymbol{L}_{\text {opt }}} \\
& \boldsymbol{P}_{\text {out }}=\boldsymbol{P}_{\text {in }}-\left(\boldsymbol{P}_{\text {in }}-\boldsymbol{P}_{\text {opt }}\right) \times \frac{\boldsymbol{L}}{\boldsymbol{L}+\boldsymbol{L}_{\text {opt }}}
\end{aligned}
$$

where $L_{i p t}=0.053 \mathrm{~m}$ and $L_{\text {opt }}=0.053 \mathrm{~m}$ for the $3-\mathrm{mm}$ inner diameter test section, and $L_{i p t}=0.063 \mathrm{~m}$ and $L_{o p t}=0.063 \mathrm{~m}$ for the 6 and 9-mm inner diameter ones.

Experimental errors are estimated to be $\pm 1 \mathrm{~K}$ in inner tube surface temperature and $\pm 2 \%$ in heat flux. Inlet flow velocity, inlet and outlet subcoolings, inlet and outlet pressures, and coefficient of ramp heat input and step height of heat input were measured within the accuracy $\pm 2 \%, \pm 1 \mathrm{~K}, \pm 1$ $\mathrm{kPa}$ and $\pm 2 \%$ respectively. 


\section{EXPERIMENTAL RESULTS AND DISCUSSION}

\subsection{Experimental Conditions}

Transient heat transfer processes were measured for the test tubes by the ramp-wise heat input $(Q=\alpha t)$ and the stepwise one $\left(Q=Q_{s}\right)$. The coefficients of ramp heat input, $\alpha$, ranged from $6.21 \times 10^{8}$ to $1.63 \times 10^{12} \mathrm{~W} / \mathrm{m}^{3} \mathrm{~s}$ and the step heights of heat input per unit volume, $Q_{s}$, ranged from $2.95 \times 10^{10}$ to $7.67 \times 10^{10} \mathrm{~W} / \mathrm{m}^{3}$. The increase of coefficient of ramp heat input means an increase in the rate of increasing heat input. The initial heat flux for the stepwise transient is zero $\mathrm{W} / \mathrm{m}^{2}$. The initial experimental conditions such as inlet flow velocity, inlet subcooling, outlet pressure, coefficient of ramp heat input and step height of heat input per unit volume for the flow boiling CHF experiments were determined independently each other before each experimental run.

The experimental conditions were as follows:

$\begin{array}{ll}\text { Heat Input Waveform } & \text { Ramp-wise heat input and stepwise one } \\ \text { Heater Material } & \text { 304 stainless steel } \\ \text { Surface Condition } & \text { Rough finished inner surface (commercial finish) } \\ \text { Surface Roughness } & 3.18 \mu \mathrm{m} \text { for } R a, 27.28 \mu \mathrm{m} \text { for } R \max \text { and } 21.16 \mu \mathrm{m} \text { for } R z \\ \text { Inner Diameter }(d) & 3,6 \text { and } 9 \mathrm{~mm} \\ \text { Heated Length }(L) & 33.15,59.5 \text { and } 49.3 \mathrm{~mm} \\ \text { L/d } & 11.05,9.92 \text { and } 5.48 \\ \text { Wall Thickness }(\delta) & 0.5,0.5 \text { and } 0.3 \mathrm{~mm}\end{array}$




\begin{tabular}{|c|c|}
\hline Inlet flow velocity $(u)$ & $4.0,6.9,9.9$ and $13.3 \mathrm{~m} / \mathrm{s}$ \\
\hline Inlet Pressure $\left(P_{\text {in }}\right)$ & 742.2 to $1293.41 \mathrm{kPa}$ \\
\hline Outlet Pressure $\left(P_{\text {out }}\right)$ & 735.08 to $1045.97 \mathrm{kPa}$ \\
\hline Inlet Subcooling $\left(\Delta T_{\text {sub,in }}\right)$ & 86.8 to $153.3 \mathrm{~K}$ \\
\hline Outlet Subcooling $\left(\Delta T_{\text {sub,out }}\right)$ & 78.11 to $144.82 \mathrm{~K}$ \\
\hline Inlet Liquid Temperature $\left(T_{i n}\right)$ & 290.27 to $356.77 \mathrm{~K}$ \\
\hline
\end{tabular}

$Q=\alpha t, \alpha=6.21 \times 10^{8}$ to $1.63 \times 10^{12} \mathrm{~W} / \mathrm{m}^{3} \mathrm{~s}$ for the ramp-wise heat input $Q=Q_{s}, Q_{s}=0 \mathrm{~W} / \mathrm{m}^{3}$ at $t=0 \mathrm{~s}$ and $Q_{s}=2.95 \times 10^{10}$ to $7.67 \times 10^{10} \mathrm{~W} / \mathrm{m}^{3}$ at $t>0 \mathrm{~s}$ for the stepwise one

\subsection{Transient CHF}

The transient critical heat fluxes, $q_{c r, s u b}$, of the subcooled water flow boiling for the wide ranges of the exponentially increasing heat inputs $\left(Q_{0} \exp (t / \tau), \tau=16.82 \mathrm{~ms}\right.$ to $\left.15.52 \mathrm{~s}\right)$, the flow velocities $(u=4.0$ to $13.3 \mathrm{~m} / \mathrm{s})$, the inlet subcoolings $\left(\Delta T_{\text {sub,in }}=68.08\right.$ to $\left.161.12 \mathrm{~K}\right)$ and the inlet pressures $\left(P_{i n}=718.31\right.$ to $\left.1314.62 \mathrm{kPa}\right)$ were systematically measured. The SUS304 tubes of the inner diameters ( $d=3,6,9$ and $12 \mathrm{~mm}$ ), heated lengths ( $L=33.15$ to $132.9 \mathrm{~mm}), L / d=5.48$ to 11.08 and wall thickness $(\delta=0.3$ and $0.5 \mathrm{~mm}$ ) with the rough finished inner surface (Surface roughness, $R a=3.18 \mu \mathrm{m})$ were used. The relation between the ratios of the difference between the transient CHFs and the steady state ones to the steady state ones, $\left(q_{c r, s u b}-q_{c r, s u b, s t}\right) / q_{c r, s u b, s t}$, and the exponential period, $\tau$, has been clarified as shown in Eq. (3). The transient CHF data were compared with the values calculated by the steady state CHF correlations against inlet 
subcooling, Eq. (1), and outlet subcooling, Eq. (2). The transient CHF correlations against inlet subcooling, Eq. (4), and outlet subcooling, Eq. (5), have been derived on the basis of the experimental data for the exponentially increasing heat input [22-25].

\subsubsection{General expression for various heat input waveforms}

Sakurai et al. [27, 28], Mizukami and Tanaka [29] and Ohya et al. [30] reported that the transient heat transfer characteristics such as incipient boiling superheat and critical heat flux for various heat inputs can be generally treated by introducing the reduced time, $\omega_{p}$, defined as follows:

$$
\omega_{p}=\int_{0}^{t} Q(t) d t / Q(t)
$$

The reduced time, $\omega_{p}$, for exponentially increasing heat input is the exponential period, $\tau$, independent of time, and the values of $\omega_{p}$ for ramp-wise and stepwise heat inputs are $t / 2$ and $t$, respectively.

The empirical correlation of the ratio of the difference between the transient CHF and the steady state one to the steady state one, Eq. (3), and the transient CHF correlations against inlet subcooling, Eq. (4), and outlet subcooling, Eq. (5), on the basis of experimental data for the exponentially increasing heat input are modified for various heat input waveforms as follows:

$$
\frac{q_{c r, s u b}-q_{c r, s u b, s t}}{q_{c r, s u b, s t}}=11.4 t^{*-0.6}
$$




$$
B o=C_{1} D^{*-0.1} W e^{-0.3}\left(\frac{L}{d}\right)^{-0.1} e^{-\frac{(L / d)}{C_{2} R e^{0.4}}} S c^{* C_{3}} \times\left(1+11.4 t^{*-0.6}\right)
$$

if inlet subcooling is known $\left(\Delta T_{\text {sub,in }} \geq 40 \mathrm{~K}\right)$

$$
B o=0.082 D *-0.1 W e^{-0.3}\left(\frac{L}{d}\right)^{-0.1} S c^{0.7} \times\left(1+6.34 t^{*-0.6}\right)
$$

$$
\text { if outlet subcooling is known }\left(\Delta T_{\text {sub,out }} \geq 30 \mathrm{~K}\right)
$$

where $t^{*}$ is the non-dimensional reduced time, $t^{*}=\omega_{p} u /\left\{\sigma / g /\left(\rho_{l}-\rho_{g}\right)\right\}^{0.5}$.

\subsubsection{Ramp-wise heat input}

The transient critical heat fluxes, $q_{c r, s u b}$, of the subcooled water flow boiling for the wide ranges of the coefficients of ramp heat input $\left(Q=\alpha t, \alpha=6.21 \times 10^{8}\right.$ to $\left.1.63 \times 10^{12} \mathrm{~W} / \mathrm{m}^{3} \mathrm{~s}\right)$, the flow velocities $(u=4.0$ to $13.3 \mathrm{~m} / \mathrm{s})$, the inlet subcoolings $\left(\Delta T_{\text {sub,in }}=86.8\right.$ to $\left.161.58 \mathrm{~K}\right)$ and the inlet pressures $\left(P_{i n}=742.20\right.$ to $\left.1293.41 \mathrm{kPa}\right)$ were systematically measured. The SUS304 tubes of the inner diameters $(d=3,6$ and $9 \mathrm{~mm})$, heated lengths $(L=33.15,59.5$ and $49.3 \mathrm{~mm}), L / d=11.05$, 9.92 and 5.48, and wall thickness $(\delta=0.5,0.5$ and $0.3 \mathrm{~mm})$ with the rough finished inner surface (Surface roughness, $R a=3.18 \mu \mathrm{m}$ ) were used.

In case of Inlet subcooling: The transient CHFs, $q_{c r, s u b}$, for $d=6 \mathrm{~mm}$ with $L=59.5 \mathrm{~mm}$ at the inlet subcooling of around $142 \mathrm{~K}$ are shown versus the reduced time for ramp-wise heat input, $\omega_{p}$ $\left(=t_{c r} / 2\right)$, with the flow velocities of 4.0, 6.9, 9.9 and $13.3 \mathrm{~m} / \mathrm{s}$ in Fig. 5. The figure also illustrates the trends in the variation of CHF with decreasing reduced time. The transient CHFs become 
higher with a decrease in the reduced time at a fixed $u$. The CHFs are almost constant for the reduced time with ramp-wise heat input, $\omega_{p}$, higher than $800 \mathrm{~ms}$, and then increase with a decrease in the $\omega_{p}$. Those show nearly the same trend of dependence on CHF data for the exponentially increasing heat input with $d=3,6,9$ and $12 \mathrm{~mm}$, although the abscissa of the figure was replaced the exponential period for the exponentially increasing heat input, $\tau$, with the reduced time for ramp-wise heat input, $t_{c r} / 2$. The transient CHFs in the whole experimental range become higher with an increase in flow velocity at a fixed reduced time. The curves given by the steady state and transient CHF correlations against inlet subcooling, Eqs. (1) and (14), at each flow velocity are shown in Fig. 5 for comparison. The CHF data for the $\omega_{p}$ higher than $800 \mathrm{~ms}$ are in good agreement with the values given by Eq. (1) and those for the wide range of the reduced times $\left(\omega_{p}=0.0648\right.$ to $\left.20.5 \mathrm{~s}\right)$ are almost in good agreement with the values given by Eq. (14), respectively. Equation (14) was derived on the basis of experimental data for the exponentially increasing heat input $\left(Q_{0} \exp (t / \tau), \tau=16.8 \mathrm{~ms}\right.$ to $\left.15.5 \mathrm{~s}\right)$.

For power transient experiments, the rate of increasing heat input is very high. It takes time to form the fully developed temperature profile in the test tube because the test tube has some heat capacity. Then the temperature profile in the thermal boundary layer on the test tube surface grows, and vaporization occurs. And furthermore, it is seen that the phenomenon occurs at some critical velocity in the vapor phase when the vapor jets start interfering with each other. It takes time to occur the hydrodynamic instability on the vapor-liquid interface at the CHF. Namely, it is explained to be as a result of the time lag of the formation of the transient critical heat flux for the increasing rate of the heat input. Figure 6 shows the influence of the non-dimensional reduced time for ramp-wise heat input, $t^{*}$, on the ratios of the difference between the transient 
CHFs, $q_{c r, s u b}$, and the steady state ones, $q_{c r, s u b, s t}$, to the $q_{c r, s u b, s t},\left(q_{c r, s u b}-q_{c r, s u b, s t}\right) / q_{c r, s u b, s t}$, for $d=6$ $\mathrm{mm}$ at the fixed inlet subcooling of around $142 \mathrm{~K}$. The ratios for the non-dimensional reduced time ranging from 128.2 to $2.38 \times 10^{4}$ were shown versus the $t^{*}$ with the flow velocity as a parameter. As shown in Fig. 6, the values of $\left(q_{c r, s u b}-q_{c r, s u b, s t}\right) / q_{c r, s u b, s t}$ become linearly higher with the decrease in the $t^{*}$. The values of $\left(q_{c r, s u b}-q_{c r, s u b, s t}\right) / q_{c r, s u b, s t}$ obtained from Eq. (13) are shown as solid curve in Fig. 6 for comparison. The transient CHF data for the $t^{*}$ ranging from 128.2 to $2.38 \times 10^{4}$ are in good agreement with the values obtained by the equation. Equation (13) was also derived based on the experimental data for the exponentially increasing heat input.

The ratios of transient CHF data for wide exponential period (208 points) to the corresponding values calculated by the steady state CHF correlation against inlet subcooling, Eq. (1), are shown versus the non-dimensional reduced time, $t^{*}$, in Fig. 7. The ratios are almost constant for the $t^{*}$ greater than around 1500 and equivalent to unity, and it becomes higher with the decrease in non-dimensional reduced time from around 1500. And the values of the transient CHF almost become two times as large as the steady state ones at the non-dimensional reduced time of 57.8 . The curve given by the transient CHF correlation against inlet subcooling, Eq. (14), is shown in Fig. 7 for comparison. The CHF data for the wide range of the reduced times are almost in good agreement with the values given by Eq. (14).

The ratios of transient CHF data for $d=3,6$ and $9 \mathrm{~mm}$ and $L=33.15,59.5$ and $49.3 \mathrm{~mm}$ $(L / d=11.05,9.92$ and 5.48) to the values calculated from the transient CHF correlation against inlet subcooling, Eq. (14), are shown versus the $t^{*}$ at the inlet pressures of $742 \mathrm{kPa}$ to $1.29 \mathrm{MPa}$ in Fig. 8. This correlation can describe not only the transient CHF data (473 points) with the 
exponentially increasing heat input but also those with the ramp-wise heat input (208 points) obtained in this work for the wide range of the non-dimensional reduced times $\left(t^{*}=37.3\right.$ to $\left.1.94 \times 10^{5}\right)$ and the flow velocities $(u=4.0$ to $13.3 \mathrm{~m} / \mathrm{s})$ at $86.8 \mathrm{~K} \leq \Delta T_{\text {sub,in }} \leq 161.6 \mathrm{~K}$ within $15 \%$ difference as shown in Fig. 8.

In case of Outlet subcooling: The ratios of transient CHF data for inner diameters $(d=3,6$ and 9 $\mathrm{mm})$, heated lengths $(L=33.15,59.5$ and $49.3 \mathrm{~mm})$ and $L / d(=11.05,9.92$ and 5.48) to the values calculated from the steady state CHF correlation against outlet subcooling, Eq. (2), are shown versus $t^{*}$ with $\Delta T_{\text {sub,out }}$ ranging from $78.11 \mathrm{~K}$ to $144.8 \mathrm{~K}$ at the outlet pressure of around $800 \mathrm{kPa}$ in Fig. 9. The ratios for $d=3,6$ and $9 \mathrm{~mm}$ are also constant for the non-dimensional reduced time for ramp-wise heat input, $t^{*}$, higher than 500 and equivalent to unity, and they become higher with the decrease in the non-dimensional reduced time for ramp-wise heat input from around 500. And in case of the ramp-wise heat input, the values of the transient $\mathrm{CHF}$ also become two times as large as the steady state ones at the non-dimensional reduced time for ramp-wise heat input of around 21.7. The curve given by the transient CHF correlation against outlet subcooling, Eq. (15), is shown in Fig. 8 for comparison. The CHF data for the wide range of the reduced times are almost in good agreement with the values given by Eq. (15).

The transient CHF correlation against outlet subcooling, Eq. (15), was derived based on the experimental data for the exponentially increasing heat input. To confirm the applicability of Eq. (15) to the transient CHF data for ramp-wise heat input, the ratios of these CHF data (208 points) for $d=3,6$ and $9 \mathrm{~mm}$ to the corresponding values calculated by Eq. (15) are shown versus $t^{*}$ in Fig. 10. Most of the data are within $\pm 15 \%$ difference for $37.3 \leq t^{*} \leq 1.94 \times 10^{5}$. 


\subsubsection{Stepwise heat input}

The transient critical heat fluxes, $q_{c r, s u b}$, of the subcooled water flow boiling for the wide ranges of the step heights of heat input per unit volume $\left(Q=Q_{s}, Q_{s}=0 \mathrm{~W} / \mathrm{m}^{3}\right.$ at $t=0 \mathrm{~s}$ and $Q_{s}=2.95 \times 10^{10}$ to $7.67 \times 10^{10} \mathrm{~W} / \mathrm{m}^{3}$ at $\left.t>0 \mathrm{~s}\right)$, the flow velocities $(u=4.0$ to $13.3 \mathrm{~m} / \mathrm{s})$, the inlet subcoolings $\left(\Delta T_{\text {sub,in }}=\right.$ 140.32 to $154.24 \mathrm{~K})$ and the inlet pressures $\left(P_{i n}=729.13\right.$ to $\left.1016.97 \mathrm{kPa}\right)$ were systematically measured. The SUS304 tubes of the inner diameter $(d=6 \mathrm{~mm})$, heated length $(L=59.5 \mathrm{~mm})$, $L / d=9.92$ and wall thickness $(\delta=0.5 \mathrm{~mm})$ with the rough finished inner surface (Surface roughness, $R a=3.18 \mu \mathrm{m})$ were used.

In case of Inlet subcooling: Figure 11 shows the transient CHFs, $q_{c r, s u b}$, for the test tube inner diameter $(d=6 \mathrm{~mm})$, the heated length $(L=59.5 \mathrm{~mm}), L / d(=9.92)$ and the wall thickness $(\delta=0.5$ $\mathrm{mm}$ ) obtained for the reduced time with stepwise heat input, $\omega_{p}\left(=t_{c r}\right)$, ranging from $63 \mathrm{~ms}$ to $11.37 \mathrm{~s}$ at the inlet subcooling, $\Delta T_{\text {sub,in }}$, of around $147 \mathrm{~K}$. The corresponding curves for the flow velocities obtained from the steady state and transient CHF correlations against inlet subcooling, Eqs. (1) and (14), are also shown in the figure for comparison. The $q_{c r, s u b}$ for the $\omega_{p}$ higher than $800 \mathrm{~ms}$ are in good agreement with the values given by Eq. (1) and those are well expressed by Eq. (14) in the experimental range $\left(\omega_{p}=0.063\right.$ to $\left.11.4 \mathrm{~s}\right)$, although the abscissa of the figure was replaced the reduced time for ramp-wise heat input, $\omega_{p}\left(=t_{c r} / 2\right)$, with the reduced time for stepwise heat input, $\omega_{p}\left(=t_{c r}\right)$. 
The ratios of the transient CHF data (105 points) for the stepwise heat input to the corresponding values calculated from the transient CHF correlation against inlet subcooling, Eq. (14), are shown versus the non-dimensional reduced time for stepwise heat input, $t^{*}$, in Fig. 12. Most of the data for the stepwise heat input $\left(Q=Q_{s}\right)$ are within $15 \%$ difference of Eq. (14) for the wide range of the non-dimensional reduced times, $t^{*},\left(=126.0\right.$ to $\left.3.38 \times 10^{4}\right)$.

In case of Outlet subcooling: The ratios of the transient CHF data for the wide range of reduced times with the stepwise heat input (105 points) to the corresponding values calculated from the transient CHF correlation against outlet subcooling, Eq. (15), are shown versus the nondimensional reduced time for the stepwise heat input, $t^{*}$, in Fig. 13. Most of the data for the stepwise heat input $\left(Q=Q_{s}, t^{*}=126.0\right.$ to $\left.3.38 \times 10^{4}\right)$ are within $15 \%$ difference of Eq. (15).

\subsection{Discussion}

In the transient $\mathrm{CHF}$ experiments with various heat input waveforms such as the exponentially increasing heat input, the ramp-wise one and the stepwise one, the test tube was heated with various heating rates (gradually to instantaneously) by an increasing the current from a direct current source (DC 35 V- 3000 A) in this work. To see the effect of heat input waveform more clearly, the transient CHFs, $q_{c r, s u b}$, for the exponentially increasing heat input, the ramp-wise one and the stepwise one on the test tube inner diameter $(d=6 \mathrm{~mm})$, the heated length $(L=59.5 \mathrm{~mm})$, $L / d(=9.92)$ with the rough finished inner surface at flow velocities of 4 and $13.3 \mathrm{~m} / \mathrm{s}$ are shown versus the reduced time, $\omega_{p}$, as each symbol in Fig. 14. And the ratios of $q_{c r, s u b}$ to the values calculated by the transient CHF correlation against inlet subcooling, Eq. (14), and those of $q_{c r, s u b}$ 
to the values calculated by the transient CHF correlation against outlet subcooling, Eq. (15), for the exponentially increasing heat input, the ramp-wise one and the stepwise one at flow velocities of 4 and $13.3 \mathrm{~m} / \mathrm{s}$ are also shown versus the non-dimensional reduced time, $t^{*}$, as each symbol in Figs. 15 and 16, respectively. Little effect of heat input waveform can be seen for the reduced time, $\omega_{p}$, ranging from 0.038 to $20.5 \mathrm{~s}$ and the non-dimensional reduced time, $t^{*}$, ranging from 68.7 to $1.16 \times 10^{5}$, although the heat input waveform was varied as the exponentially increasing heat input, the ramp-wise one and the stepwise one.

The shorter reduced time for the exponentially increasing heat input, the ramp-wise one and the stepwise one induces instantaneously a very high heating rate in the test tube. We have supposed before this study that heating rate will affect the incipient boiling superheat and the nucleate boiling heat transfer up to the CHF. Incipient boiling superheat may shift to a high value at a high heating rate, and direct transition to film boiling may occur in such a case. That may be the cause of very low published data $[3,5,7]$ that were about a half or lower of those given by our steady state CHF equations, Eqs. (1) and (2), as shown in Appendix A. 3. However, no direct transition to film boiling was observed for the various heat input waveforms and inner-diameters $(d=3,6,9$ and $12 \mathrm{~mm})$ with the rough finished surface $(R a=3.18 \mu \mathrm{m})$ used here even at the highest heating rate $\left(t^{*}=37.3\right)$ as shown in Figs. 5 to 16 . Reproducibility of the data at a higher heating rate with various heat input waveform needs to be further studied. And, it becomes very important to confirm the lower limit of the reduced time, $\omega_{p}$, for the applicability of transient CHF correlations, Eqs. (14) and (15), to keep on high heat flux heat removal. 
Meanwhile, actually burned out test surface showed that burnout occurred at a local position near the exit of the test tube. Distribution of temperature along the inner surface of the test tube would become more non-uniform for the test tube. The inner surface temperature at the exit of the test tube would become higher, as the outlet liquid temperature becomes higher. The non-uniformity for the test tube may be the cause of the lower CHF. To see the axial variation of the inner surface temperature and the heat flux, the inner surface temperatures and the heat fluxes for intervals divided the heated length of the test tube into several parts will be clarified in near future with a precision measurement.

\section{CONCLUSIONS}

The transient critical heat fluxes (CHFs) of subcooled water flow boiling for the ramp-wise heat input $(Q=\alpha t)$ and the stepwise one $\left(Q=Q_{s}\right)$ with the inner-diameters $(d=3,6$ and $9 \mathrm{~mm})$, the heated lengths $(L=33.15,59.5$ and $49.3 \mathrm{~mm})$ and $L / d(=11.05,9.92$ and 5.48) were systematically measured for the wide ranges of the flow velocities $(u=4.0$ to $13.3 \mathrm{~m} / \mathrm{s})$, the inlet subcoolings $\left(\Delta T_{\text {sub,in }}=86.8\right.$ to $\left.153.3 \mathrm{~K}\right)$, the outlet subcoolings $\left(\Delta T_{\text {sub out }}=78.11\right.$ to $\left.144.82 \mathrm{~K}\right)$, the inlet pressures $\left(P_{\text {in }}=742.2\right.$ to $\left.1293.41 \mathrm{kPa}\right)$, the outlet pressures $\left(P_{\text {out }}=735.08\right.$ to $\left.1045.97 \mathrm{kPa}\right)$, the coefficients of ramp-wise heat input $\left(Q=\alpha t, \alpha=6.21 \times 10^{8}\right.$ to $\left.1.63 \times 10^{12} \mathrm{~W} / \mathrm{m}^{3} \mathrm{~s}\right)$ and the step heights of heat input per unit volume $\left(Q=Q_{s}, Q_{s}=0 \mathrm{~W} / \mathrm{m}^{3}\right.$ at $t=0 \mathrm{~s}$ and $Q_{s}=2.95 \times 10^{10}$ to $7.67 \times 10^{10}$ $\mathrm{W} / \mathrm{m}^{3}$ at $\left.t>0 \mathrm{~s}\right)$. Experimental results lead to the following conclusions.

1) The transient CHFs, $q_{c r, s u b}$, for the ramp-wise heat input and the stepwise one are almost constant for the reduced times with ramp-wise heat input and stepwise one, $\omega_{p}\left(=t_{c r} / 2\right.$ and $\left.t_{c r}\right)$, 
greater than around $800 \mathrm{~ms}$ and they become higher with the decrease in the reduced time from around $800 \mathrm{~ms}$ respectively. The transient CHFs become higher with an increase in flow velocity at a fixed reduced time.

2) The ratios of transient CHF data (313 points) for the wide ranges of the coefficients of rampwise heat input $\left(Q=\alpha t, \alpha=6.21 \times 10^{8}\right.$ to $\left.1.63 \times 10^{12} \mathrm{~W} / \mathrm{m}^{3} \mathrm{~s}\right)$, the step heights of heat input per unit volume $\left(Q=Q_{s}, Q_{s}=0 \mathrm{~W} / \mathrm{m}^{3}\right.$ at $t=0 \mathrm{~s}$ and $Q_{s}=2.95 \times 10^{10}$ to $7.67 \times 10^{10} \mathrm{~W} / \mathrm{m}^{3}$ at $\left.t>0 \mathrm{~s}\right)$ and the inner diameters $(d=3,6$ and $9 \mathrm{~mm})$ to the corresponding values calculated from the steady state CHF correlations against inlet subcooling, Eq. (1), and outlet subcooling, Eq. (2), are constant for the non-dimensional reduced time, $t^{*}$, greater than 1500 and 500, and equivalent to unity, and they become higher with the decrease in non-dimensional reduced time from the values up to two times of the steady state ones at the non-dimensional reduced times of 57.8 and 21.7 , respectively.

3) The transient CHF correlations against inlet subcooling, Eq. (14), and outlet subcooling, Eq. (15), were confirmed to be applicable to the transient CHF data for the ramp-wise heat input and the stepwise one with the wide range of the non-dimensional reduced times $(37.3 \leq$ $t^{*} \leq 1.94 \times 10^{5}$ and $\left.126.0 \leq t^{*} \leq 3.38 \times 10^{4}\right)$. Most of the data for the ramp-wise heat input $(208$ points) and the stepwise one (105 points) are within $15 \%$ difference of Eqs. (14) and (15) respectively.

4) Little effect of heat input waveform can be seen for the reduced time, $\omega_{p}$, ranging from 0.0648 to $20.5 \mathrm{~s}$ and the non-dimensional reduced time, $t^{*}$, ranging from 37.3 to $1.94 \times 10^{5}$, although 
the heat input waveform was varied as the exponentially increasing heat input, the ramp-wise one and the stepwise one.

5) Neither direct transition to film boiling nor trend of a decrease in CHF with a decrease in the reduced time in smaller reduced time was observed for the various heat input waveforms and inner-diameters $(d=3,6$ and $9 \mathrm{~mm})$ with the rough finished surface $(R a=3.18 \mu \mathrm{m})$ used here even at the highest heating rate $\left(t^{*}=37.3\right)$.

\section{NOMENCLATURE}

$a, b, c$ fitted constant in Eqs. (A-4) and (A-5) $\quad L \quad$ heated length, $\mathrm{m}$

Bo $=q_{c r, s u b} / G h_{f g}$, boiling number $\quad L_{e} \quad$ entrance length, $\mathrm{m}$

$C_{1}, C_{2}, C_{3}$ constant in Eqs. (1), (4) and (14) $L_{i p t} \quad$ distance between inlet pressure

c specific heat, $\mathrm{J} / \mathrm{kg} \mathrm{K} \quad$ transducer and inlet of the heated

$c_{p} \quad$ specific heat at constant pressure, $\mathrm{J} / \mathrm{kg} \mathrm{K} \quad$ section, $\mathrm{m}$

$D^{*} \quad=d /\left\{\sigma / g /\left(\rho_{l}-\rho_{g}\right)\right\}^{0.5}$, non-dimensional $\quad L_{\text {opt }} \quad$ distance between outlet pressure

diameter

transducer and outlet of the heated

$d \quad$ test tube inner diameter, $\mathrm{m}$

section, $\mathrm{m}$

$G \quad=\rho_{l} u$, mass flux, $\mathrm{kg} / \mathrm{m}^{2} \mathrm{~s}$

$\mathrm{O}_{2} \quad$ dissolved oxygen concentration, ppm

$g \quad$ acceleration of gravity, $\mathrm{m} / \mathrm{s}^{2}$

$P \quad$ pressure, $\mathrm{kPa}$

$h_{f g} \quad$ latent heat of vaporization, $\mathrm{J} / \mathrm{kg}$

$P_{\text {in }} \quad$ pressure at inlet of heated section, $\mathrm{kPa}$

I current flowing through standard

$P_{i p t} \quad$ pressure measured by inlet pressure

resistance, $\mathrm{A}$ transducer, $\mathrm{kPa}$ 
$P_{\text {out }} \quad$ pressure at outlet of heated section, $\mathrm{kPa} \quad \operatorname{Re} \quad=G d / \mu_{l}$, Reynolds number

$P_{\text {opt }} \quad$ pressure measured by outlet pressure $\quad S \quad$ surface area, $\mathrm{m}^{2}$ transducer, $\mathrm{kPa}$

$p^{*} \quad=\tau u /\left\{\sigma / g /\left(\rho_{l}-\rho_{g}\right)\right\}^{0.5}$, non-dimensional exponential period

$Q \quad$ heat input per unit volume, $\mathrm{W} / \mathrm{m}^{3}$

$Q_{0} \quad$ initial exponential heat input, $\mathrm{W} / \mathrm{m}^{3}$

$Q_{s} \quad$ step height of heat input per unit volume, $\mathrm{W} / \mathrm{m}^{3}$

$Q_{v} \quad$ heat input per unit volume, $\mathrm{W} / \mathrm{m}^{3}$

$q \quad$ heat flux, $\mathrm{W} / \mathrm{m}^{2}$

$q_{c r, s u b} \quad$ transient critical heat flux for subcooled condition, $\mathrm{W} / \mathrm{m}^{2}$

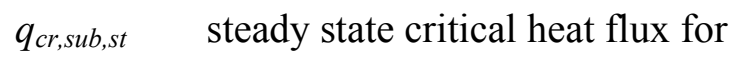
subcooled condition, $\mathrm{W} / \mathrm{m}^{2}$

$R_{1}$ to $R_{3}$ resistance in a double bridge circuit, $\Omega$

$R a \quad$ average roughness, $\mu \mathrm{m}$

Rmax maximum roughness depth, $\mu \mathrm{m}$

$R_{T} \quad$ resistance in a double bridge circuit, $\Omega$

$\left(R_{T}\right)_{T R I P} \quad$ trip resistance, $\Omega$

$R z \quad$ mean roughness depth, $\mu \mathrm{m}$
Sc $\quad=c_{p l}\left(\Delta T_{\text {sub,out }}\right)_{c a l} / h_{f g},=c_{p l} \Delta T_{\text {sub out }} / h_{f g}$, non-dimensional outlet subcooling

$S c^{*} \quad=c_{p l} \Delta T_{\text {sub,in }} / h_{f g}$, non-dimensional inlet subcooling

$T \quad$ temperature of the test tube, $\mathrm{K}$

$\overline{\boldsymbol{T}} \quad$ average temperature of the test tube, $\mathrm{K}$

$T_{\text {in }} \quad$ inlet liquid temperature, $\mathrm{K}$

$T_{\text {out }} \quad$ outlet liquid temperature, $\mathrm{K}$

$T_{s} \quad$ inner surface temperature, $\mathrm{K}$

$T_{\text {sat }} \quad$ saturation temperature, $\mathrm{K}$

$T_{\text {TRIP }} \quad$ trip temperature, $\mathrm{K}$

$t \quad$ time, $\mathrm{s}$

$t_{\text {lag }} \quad$ time lag, $\mathrm{s}$

$t^{*} \quad=\omega_{p} u /\left\{\sigma / g /\left(\rho_{l}-\rho_{g}\right)\right\}^{0.5}$, non-dimensional reduced time

$\Delta T \quad$ step temperature, $\mathrm{K}$

$\Delta T_{\text {sub,in }}=\left(T_{\text {sat }}-T_{\text {in }}\right)$, inlet liquid subcooling, $\mathrm{K}$ $\Delta T_{\text {sub,out }}=\left(T_{\text {sat }}-T_{\text {out }}\right)$, outlet liquid subcooling,

K

$u$ flow velocity, $\mathrm{m} / \mathrm{s}$

$V \quad$ volume, $\mathrm{m}^{3}$ 


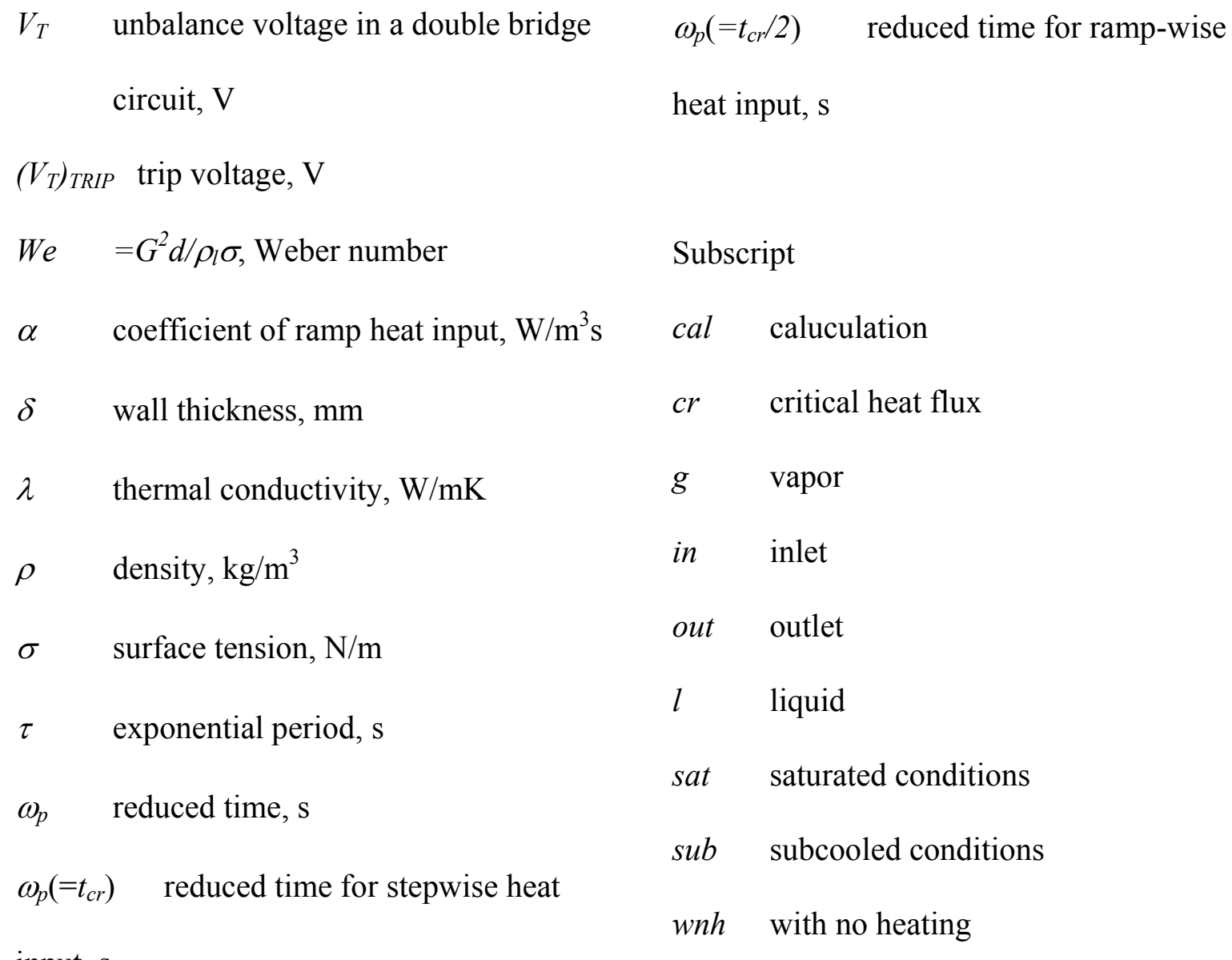
input, $\mathrm{s}$

\section{ACKNOWLEDGMENTS}

This research was performed as a LHD joint research project of NIFS (National Institute for Fusion Science), Japan, NIFS05KFRF015, 2006. I would like to express my gratitude to Associate Professor Takashi Nakajima, Institute of Advanced Energy, Kyoto University, Japan, for his stimulating support.

\section{APPENDIX}




\section{A. 1. Method of Calculation of Preset Temperature by High-Speed Analog Computer}

The subcooled flow boiling heat transfer (HT) and transient critical heat flux (CHF) for the wide ranges of the flow velocity, the inlet subcooling, the outlet pressure, the coefficient of ramp heat input and the step height of heat input per unit volume are systematically measured. And we have given the steady state CHF correlations against inlet and outlet subcoolings based on the effects of test tube inner diameter $(d)$, flow velocity $(u)$, inlet and outlet subcoolings $\left(\Delta T_{\text {sub,in }}\right.$ and $\left.\Delta T_{\text {sub,out }}\right)$ and ratio of heated length to inner diameter $(L / d)$ on CHF. The relation between the steady state CHF, $q_{c r, s u b, s t}$, and the average temperature of the test tube at CHF, $\overline{\boldsymbol{T}}_{c r}$, for a given experimental condition could be roughly estimated by using boiling curve database and $\mathrm{CHF}$ correlation. The power trip temperature (preset temperature) is given to the heat input control block (a high-speed analog computer) in Fig. 4 as follows:

$$
T_{T R I P}=\bar{T}_{c r}+\Delta T
$$

where, $\Delta T$ is increased step by step from 0 to some hundred Kelvins until the measured test tube surface temperature rapidly jumps from the nucleate boiling heat transfer regime to the film boiling one. The maximum value of the heat flux, $q$, which is larger than the $q_{c r, s u b, s t}$ is given and that of the heat input per unit volume, $Q_{v}$, for the test tube is calculated as follows:

$$
\begin{aligned}
& q=q_{c r, s u b, s t}+\Delta q \\
& Q_{v}=q \frac{\pi d L}{\pi\left\{(d+2 \delta)^{2}-d^{2}\right\} L / 4}
\end{aligned}
$$

The electrical resistance of the test tube, $R_{T}$, is measured at various temperatures before each experiment and the relationship between the electrical resistance and temperature is calibrated by following approximate form. 


$$
R_{T}=a\left(1+b T+c T^{2}\right)
$$

where $a, b$ and $c$ are fitted values based on the measured data. The electrical resistance of power trip for the test tube,$\left(R_{T}\right)_{T R I P}$, is obtained by substituting the power trip temperature, $T_{T R I P}$, into Eq. (A-4).

$$
\left(R_{T}\right)_{T R I P}=a\left(1+b T_{T R I P}+c T_{T R I P}^{2}\right)
$$

The schematic of a double bridge circuit is shown in Fig. 4 . The current, $I$, through the standard resistance, $R_{s}$, can be regarded as that through the test tube. Therefore the heat generation of the test tube, $Q$, is expressed by the following form. The current at the power trip temperature, $I_{T R I P}$, is calculated.

$$
\begin{aligned}
& Q=I^{2}\left(R_{T}\right)_{T R I P}=Q_{v} \frac{\pi\left\{(d+2 \delta)^{2}-d^{2}\right\} L}{4} \\
& I_{T R I P}=\sqrt{Q_{v} \frac{\pi\left\{(d+2 \delta)^{2}-d^{2}\right\} L}{4\left(R_{T}\right)_{T R I P}}}
\end{aligned}
$$

where $Q_{v}$ is the heat input per unit volume $\left(\mathrm{W} / \mathrm{m}^{3}\right)$. The double bridge circuit is balanced for small current at a liquid temperature. When the direct current is supplied to the test tube, the electrical resistance of the test tube increases. As a result, the unbalance voltage, $V_{T}$, is expressed by means of Ohm's low. The power trip voltage, $\left(V_{T}\right)_{T R I P}$, at the power trip temperature is calculated as the following form.

$$
\left(V_{T}\right)_{T R I P}=\frac{I\left\{\left(R_{T}\right)_{T R I P} \times R_{2}-R_{1} \times R_{3}\right\}}{R_{2}+R_{3}}
$$

The value of $\left(V_{T}\right)_{T R I P}$ is given the comparator of the heat input control block in Fig. 4 as the preset temperature to avoid test tube damage. This procedure avoids actual burnout of the test tube. 


\section{A. 2. Evaluation of Outlet Subcooling for Power Transient Experiment}

As mentioned above, the outlet liquid temperature is measured by 1-mm o.d., sheathed, K-type thermocouple which is located at the centerline of the tube at the lower stream point of $53 \mathrm{~mm}$ from the tube outlet point for the 3-mm inner diameter test section, and at those of $63 \mathrm{~mm}$ from those points for the 6,9 and $12-\mathrm{mm}$ inner diameter ones. The outlet subcoolings experimentally measured at the steady state CHFs are compared with the average outlet subcoolings calculated from the inlet liquid temperatures in Fig. a.1. The outlet subcoolings averaged over the cross sectional area are calculated by the energy balance as follows.

$$
\left(\Delta T_{\text {sub,out }}\right)_{c a l}=T_{\text {sat }, \text { out }}-\left(T_{\text {out }}\right)_{c a l}=T_{\text {sat }, \text { out }}-\left(T_{\text {in }}+\frac{4 L q_{c r, s u b}}{u c_{p l} \rho_{l} d}\right)
$$

Thermo-physical properties are evaluated at the temperature of $\left\{T_{\text {in }}+\left(T_{\text {out }}\right)_{\text {cal }}\right\} / 2$. The measured outlet subcoolings for $d=3,6,9$ and $12 \mathrm{~mm}$ are slightly higher than the calculated ones in the whole experimental range and the differences between the measured outlet subcoolings and the calculated ones become linearly larger with an increase in the outlet subcooling in this figure. They are quite independent of the inner diameter for a wide range of the outlet subcooling, although those differences may be due to imperfect mixing. Relation between $\Delta T_{\text {sub,out }}$ and $\left(\Delta T_{\text {sub,out }}\right)_{c a l}$ is almost described by the following equation.

$$
\Delta T_{\text {sub,out }}=1.081\left(\Delta T_{\text {sub }, \text { out }}\right)_{c a l}
$$


It is confirmed that the steady state critical heat fluxes for various inner diameters, heated lengths, heat fluxes, outlet pressures and flow velocities can be generally treated by the outlet subcoolings measured at the centerline of the tube outlet. Therefore, we have adopted the outlet subcooling measured at the centerline of the tube, $\Delta T_{\text {sub,out }}$, as a standard parameter.

Figure a. 2 shows a typical photograph of the test tube burned out for power transient experiment. The dark sections near the tube outlet are the traces of the vapor patches; the local temperatures on the tube jumped to those of the film boiling region at the occurrence of CHF. The locations of the vapor patches were almost observed near the tube outlet in this experiment. The tube wall did not clearly melt down along the circumference of the tube, because the heating current to the tube was instantaneously cut off when the measured average temperature rapidly increased up to the preset temperature lower than the actual burnout temperature of the tube. By using this burnout detector, several CHF data were obtained for a single tube without the actual burnout.

Figure a. 3 shows the time variations in the inlet and outlet pressures calculated by Eqs. (10) and (11), $P_{\text {in }}$ and $P_{\text {out }}$, heat flux, $q$, and heater inner surface temperature, $T_{s}$, for $P_{\text {out }}=838 \mathrm{kPa}$, $\Delta T_{\text {sub,in }}=144 \mathrm{~K}, u=3.98 \mathrm{~m} / \mathrm{s}$ and $\tau=77.57 \mathrm{~ms}$. The values of $P_{\text {in }}$ and $P_{\text {out }}$ keep almost constant in the whole experimental range, although they oscillate violently near the CHF point. Figure a.4 shows the time variations in the inlet and outlet liquid temperatures, $T_{i n}$ and $T_{\text {out }}$, the inlet and outlet subcoolings measured, $\Delta T_{\text {sub,in }}$ and $\Delta T_{\text {sub,out }}, q$ and $T_{s}$ for $P_{\text {out }}=838 \mathrm{kPa}, \Delta T_{\text {sub,in }}=144 \mathrm{~K}$, $u=3.98 \mathrm{~m} / \mathrm{s}$ and $\tau=77.57 \mathrm{~ms}$. The values of $T_{\text {in }}$ and $\Delta T_{\text {sub,in }}$ keep almost constant in the whole experimental range, although those of $T_{\text {out }}$ and $\Delta T_{\text {sub,out }}$ become gradually higher and lower with an increase in the heat flux respectively. The outlet liquid temperatures and the outlet 
subcoolings for power transient experiment were made corrections in time to account for instrument lag because the locations of the vapor patches for the CHFs were almost observed near the tube outlet, as shown in Fig. a.2. The time lags for 3, 6, 9 and 12-mm inner diameter test sections in the experimental water loop are shown in Table 1 respectively. The values of the time lag, $t_{\text {lag }}$, for $u=4.0$ to $13.3 \mathrm{~m} / \mathrm{s}$ are 13.25 to $3.98 \mathrm{~ms}$ for $d=3 \mathrm{~mm}$ inner diameter test section, and 15.75 to $4.73 \mathrm{~ms}$ for $d=6,9$ and $12 \mathrm{~mm}$ inner diameter ones respectively.

\section{A. 3. Comparison of our Steady State CHF Correlations with Other Workers' CHF Data}

The values derived from the steady state CHF correlation against the outlet subcooling, Eq. (2), are compared with the experimental data for $d=2.5$ to $5 \mathrm{~mm}$ with $L / d=20$ to 40 by Celata et al. [3] and those for $d=0.33$ to $2.667 \mathrm{~mm}$ with $L / d=1.66$ to 49.78 by Vandervort et al. [5] with $d, P_{\text {out }}$ and $G$ as a parameter in Figs. a.5 to a.7. And those derived from the steady state CHF correlations against the inlet and outlet subcoolings, Eqs. (1) and (2), are compared with the experimental data for $d=0.406$ to $2.54 \mathrm{~mm}$ with $L / d=2.4$ to 34.1 by Mudawar and Bowers [7] with $d, P_{\text {out }}$ and $G$ as a parameter in Figs. a.8 and a.9. Their experimental data are widely distributed with no systematic tendency in the whole experimental range, although most of our data are almost within $15 \%$ for $\Delta T_{\text {sub,in }} \geq 40 \mathrm{~K}$ and $\Delta T_{\text {sub,out }} \geq 30 \mathrm{~K}$. It is suggested from these facts that the CHF may occur not only based on the hydrodynamic instability $[31,32]$ but also based on another dominant mechanism, if the experimental data contain hardly any measurement error.

\section{REFERENCES}


1. A. E. Bergles, "Subcooled Burnout in Tubes of Small Diameter," ASME Paper No. 63-WA182, pp. 1-9 (1963).

2. H. Nariai, F. Inasaka and T. Shimura, "Critical Heat Flux of Subcooled Flow Boiling in Narrow Tube," Proceedings of the 1987 ASME-JSME Thermal Engineering Joint Conference, Vol. 5, Hemisphere, New York, pp. 455-462 (1987).

3. G. P. Celata, M. Cumo and A. Mariani, "Subcooled Water Flow Boiling CHF with Very High Heat Fluxes," Revue Generale de Thermique, n’362, pp. 29-37 (1992).

4. G. P. Celata, M. Cumo and A. Mariani, "Enhancement of CHF Water Subcooled Flow Boiling in Tubes using Helically Coiled Wires," International Journal of Heat and Mass Transfer, 37, No. 1, pp. 53-67 (1994).

5. C. L. Vandervort, A. E. Bergles and M. K. Jensen, "An Experiment Study of Critical Heat Flux in Very High Heat Flux Subcooled Boiling," International Journal of Heat and Mass Transfer, 37, Suppl. 1, pp. 161-173 (1994).

6. G. P. Celata, "Critical Heat Flux in Subcooled Flow Boiling," Heat Transfer 1998, Proceedings of 11th International Heat Transfer Conference, Vol. 1, pp. 261-277 (1998).

7. I. Mudawar and M. B. Bowers, "Ultra-high Critical Heat Flux (CHF) for Subcooled Water Flow Boiling-I: CHF data and parametric effects for small diameter tubes," International Journal of Heat and Mass Transfer, 42, pp. 1405-1428 (1999).

8. I. Kataoka, A. Serizawa and A. Sakurai, "Transient Boiling Heat Transfer under Forced Convection," International Journal of Heat and Mass Transfer, 26, No. 4, pp. 583-595 (1983).

9. G. P. Celata, M. Cumo, F. D' Annibale, G. E. Farello and S. A. Said, "Critical Heat Flux Phenomena during Power Transients," Heat and Technology, 6, No. 1-2, pp. 38-69 (1988). 
10. G. P. Celata, M. Cumo, F. D' Annibale and G. E. Farello, "Critical Heat Flux in Transient Flow Boiling during Simultaneous Variations in Flow Rate and Thermal Power," Experimental Thermal and Fluid Science, 2, No. 2, pp. 134-145 (1989).

11. G. P. Celata, M. Cumo and F. D' Annibale, "A Data Set of Critical Heat Flux of Boiling R-12 in Uniformly Heated Vertical Tubes under Transient Conditions," Experimental Thermal and Fluid Science, 5, No. 1, pp. 78-107 (1992).

12. K. Hata, T. Sato, T. Tanimoto, M. Shiotsu and N. Noda, "Critical Heat Fluxes of Subcooled Water Flow Boiling against Outlet Subcooling in Short Vertical Tube," Proceedings of the 10th International Conference on Nuclear Engineering, Paper No. ICONE10-22324, pp. 110 (2002).

13. K. Hata, T. Tanimoto, H. Komori, M. Shiotsu and N. Noda, "Critical Heat Fluxes of Subcooled Water Flow Boiling against Inlet Subcooling in Short Vertical Tube," Proceedings of the 11th International Conference on Nuclear Engineering, Paper No. ICONE11-36116, pp. 1-11 (2003).

14. K. Hata, H. Komori, M. Shiotsu and N. Noda, "Critical Heat Flux of Subcooled Water Flow Boiling for High L/d Region," Proceedings of the 10th International Topical Meeting on Nuclear Reactor Thermal Hydraulics, Paper No. NURETH10-C00207, pp. 1-13 (2003).

15. K. Hata, M. Shiotsu and N. Noda, "Critical Heat Fluxes of Subcooled Water Flow Boiling against Outlet Subcooling in Short Vertical Tube," Journal of Heat Transfer, Trans. ASME, Series C, 126, pp. 312-320 (2004).

16. K. Hata, H. Komori, M. Shiotsu and N. Noda, "Critical Heat Fluxes of Subcooled Water Flow Boiling against Inlet Subcooling in Short Vertical Tube," JSME International Journal, Series B, 47, No. 2, pp. 306-315 (2004). 
17. K. Hata, H. Komori, M. Shiotsu and N. Noda, "Influence of Dissolved Gas Concentration on Subcooled Flow Boiling Critical Heat Flux in Short Vertical Tube," Proceedings of 12th International Conference on Nuclear Engineering, Paper No. ICONE12-49194, pp. 1-11 (2004).

18. K. Hata, M. Shiotsu and N. Noda, "Subcooled Flow Boiling Critical Heat Flux in Short Vertical Tube (Influence of Inner Surface Roughness)," Proceedings of 2004 ASME International Mechanical Engineering Congress and RD\&D Expo, Paper No. IMECE200461453, pp. 1-10 (2004).

19. K. Hata, M. Shiotsu and N. Noda, "Influence of Test Tube Material on Subcooled Flow Boiling Critical Heat Flux in Short Vertical Tube," Proceedings of 14th International Conference on Nuclear Engineering, Miami, Florida, USA, ICONE14-89162, pp. 1-10 (2006).

20. K. Hata, M. Shiotsu and N. Noda, "Critical Heat Flux of Subcooled Water Flow Boiling for High L/d Region," Nuclear Science and Engineering, 154, No. 1, pp. $94-109$ (2006).

21. K. Hata, M. Shiotsu and N. Noda, "Influence of Test Tube Material on Subcooled Flow Boiling Critical Heat Flux in Short Vertical Tube," Journal of Power and Energy Systems, 1, No. 1, pp. 49-63 (2007).

22. K. Hata, M. Shiotsu and N. Noda, "Influence of Heating Rate on Subcooled Flow Boiling Critical Heat Flux in a Short Vertical Tube," Proceedings of 13th International Conference on Nuclear Engineering, Beijing, China, ICONE13-50307, pp. 1-8 (2005).

23. K. Hata and N. Noda, "Subcooled flow boiling heat transfer and critical heat flux in short vertical tube with mirror finished inner surface," Proceedings of 11th International Topical 
Meeting on Nuclear Reactor Thermal Hydraulics, Paper No. NURETH11-281, pp. 1-20 (2005).

24. K. Hata, M. Shiotsu and N. Noda, "Influence of Heating Rate on Subcooled Flow Boiling Critical Heat Flux in a Short Vertical Tube," JSME International Journal, Series B, 49, No. 2, pp. 309-317 (2006).

25. K. Hata, M. Shiotsu and N. Noda, "Transient Critical Heat Fluxes of Subcooled Water Flow Boiling in a Short Vertical Tube Caused by Exponentially Increasing Heat Inputs," Proceedings of 13th International Heat Transfer Conference, Sydney, Australia, Paper No. IHTC13-BOI-07, pp. 1-13 (2006).

26. R. S. Brodkey and H. C. Hershey, Transport Phenomena, McGraw-Hill, New York, p. 568 (1988).

27. A. Sakurai, K. Mizukami and M. Shiotsu, "Experimental Studies on Transient Boiling Heat Transfer and Burnout," Heat Transfer 1970, Vol. V, B3.4, Elsevier, Amsrerdam (1970).

28. A. Sakurai, and K. Mizukami, "An Approximate Expression of Heat Transfer Coefficient by Transient Heat Conduction," Technical Reports of The Institute of Atomic Energy, Kyoto University, No. 155 (1972).

29. K. Mizukami and S. Tanaka, "Comments to the Onset of Natural Convection from Timedependent Profiles," International Journal of Heat and Mass Transfer, 19, pp. 125-126 (1976).

30. M. Ohya, K. Hata and M. Shiotsu, "Transient Heat Transfer from a Flat Plate in a Pool of FC-72," Proceedings of IPACK'01 (The Pacific Rim/ASME International Electronic Packaging Technical Conference and Exhibition), Paper No. IPACK2001-15575, pp.1-9 (2001). 
31. S.S. KUTATELADZE, Heat Transfer in Condensation and Boiling, AEC-tr-3770, USAEC (1959).

32. N. ZUBER, Hydrodynamic Aspects of Boiling Heat Transfer, AECU-4439, USAEC (1959). 


\section{Figure Captions}

Table 1 Time lag for 3, 6, 9 and $12 \mathrm{~mm}$ inner diameter test sections in the experimental water loop.

Figure 1 Schematic diagram of experimental water loop.

Figure 2 Vertical cross-sectional view of 3, 6 and 9-mm inner diameter test sections.

Figure 3 SEM photograph of the test tube with the rough finished inner surface.

Figure 4 Measurement and data processing system.

Figure 5 The $q_{c r, s u b}$ for $d=6 \mathrm{~mm}$ with ramp-wise heat input at $\Delta T_{\text {sub,in }}=142 \mathrm{~K}$ for $\omega_{p}=0.0656$ to $20.5 \mathrm{~s}$

Figure $6\left(q_{c r, s u b}-q_{c r, s u b, s t}\right) / q_{c r, s u b, s t}$ versus $t^{*}$ for $d=6 \mathrm{~mm}$ with ramp-wise heat input.

Figure 7 Ratios of $q_{c r, s u b}$ for $d=3$ to $9 \mathrm{~mm}$ with ramp-wise heat input (208 points) to calculated values by Eq. (1) versus $t^{*}$.

Figure 8 Ratios of $q_{c r, s u b}$ for $d=3$ to $9 \mathrm{~mm}$ with ramp-wise heat input (208 points) to calculated values by Eq. (14) versus $t^{*}$.

Figure 9 Ratios of $q_{c r \text { sub }}$ for $d=3$ to $9 \mathrm{~mm}$ with ramp-wise heat input (208 points) to calculated values by Eq. (2) versus $t^{*}$.

Figure 10 Ratios of $q_{c r, s u b}$ for $d=3$ to $9 \mathrm{~mm}$ with ramp-wise heat input (208 points) to calculated values by Eq. (15) versus $t^{*}$.

Figure 11 The $q_{c r, s u b}$ for $d=6 \mathrm{~mm}$ with stepwise heat input at $\Delta T_{s u b, i n}=147 \mathrm{~K}$ for $\omega_{p}=0.063$ to $4.75 \mathrm{~s}$.

Figure 12 Ratios of $q_{c r, s u b}$ for $d=6 \mathrm{~mm}$ with stepwise heat input (105 points) to calculated values by Eq. (14) versus $t^{*}$. 
Figure 13 Ratios of $q_{c r \text {,sub }}$ for $d=6 \mathrm{~mm}$ with stepwise heat input (105 points) to calculated values by Eq. (15) versus $t^{*}$.

Figure 14 The $q_{c r, s u b}$ for various heat input waveform with $\omega_{p}=0.038$ to $20.5 \mathrm{~s}$ at $u=4.0$ and 13.3 $\mathrm{m} / \mathrm{s}$.

Figure 15 Ratios of $q_{c r, s u b}$ for various heat input waveform to calculated values by Eq. (14) versus $t^{*}$.

Figure 16 Ratios of $q_{c r, s u b}$ for various heat input waveform to calculated values by Eq. (15) versus $t^{*}$.

Figure a.1 Relationship between measured outlet subcooling and calculated outlet subcooling for the inner diameter of $3,6,9$ and $12 \mathrm{~mm}$ with $L / d=11$.

Figure a.2 Typical photograph of the test tube burned out.

Figure a.3 Time variations in $P_{\text {in }}, P_{\text {out }}, q$ and $T_{s}$ for $P_{\text {out }}=838 \mathrm{kPa}, \Delta T_{\text {sub,in }}=144 \mathrm{~K}, u=3.98 \mathrm{~m} / \mathrm{s}$ and $\tau=77.57 \mathrm{~ms}$.

Figure a.4 Time variations in $T_{\text {in }}, T_{\text {out }}, \Delta T_{\text {sub,in }}, \Delta T_{\text {sub,out }}, q$ and $T_{s}$ for $P_{\text {out }}=838 \mathrm{kPa}, \Delta T_{\text {sub,in }}=144$ $\mathrm{K}, u=3.98 \mathrm{~m} / \mathrm{s}$ and $\tau=77.57 \mathrm{~ms}$.

Figure a.5 Comparison of the values derived from the steady state CHF correlation against outlet subcooling, Eq. (2), with Celata et al. experimental data [3].

Figure a.6 Comparison of the values derived from the steady state CHF correlation against outlet subcooling, Eq. (2), with Vandervolt et al. experimental data [5].

Figure a.7 Comparison of the values derived from the steady state CHF correlation against outlet subcooling, Eq. (2), with Vandervolt et al. experimental data [5], Premature failures.

Figure a.8 Comparison of the values derived from the steady state CHF correlation against inlet subcooling, Eq. (1), with Mudawar and Bowers experimental data [7]. 
Figure a.9 Comparison of the values derived from the steady state CHF correlation against outlet subcooling, Eq. (2), with Mudawar and Bowers experimental data [7]. 
Table 1 Time lag for 3, 6, 9 and $12 \mathrm{~mm}$ inner diameter test sections in the experimental water loop.

\begin{tabular}{|l|l|l|l|l|l|}
\hline \multirow{2}{*}{$d(\mathrm{~mm})$} & \multirow{2}{*}{$L_{\text {otc }}(\mathrm{mm})$} & \multicolumn{4}{|c|}{$t_{\text {lag }}(\mathrm{ms})$} \\
\cline { 3 - 6 } & & $u=4.0 \mathrm{~m} / \mathrm{s}$ & $u=6.9 \mathrm{~m} / \mathrm{s}$ & $u=9.9 \mathrm{~m} / \mathrm{s}$ & $u=13.3 \mathrm{~m} / \mathrm{s}$ \\
\hline 3 & 53 & 13.25 & 7.68 & 5.35 & 3.98 \\
\hline 6 & 63 & 15.75 & 9.13 & 6.36 & 4.73 \\
\hline 9 & 63 & 15.75 & 9.13 & 6.36 & 4.73 \\
\hline 12 & 63 & 15.75 & 9.13 & 6.36 & 4.73 \\
\hline
\end{tabular}




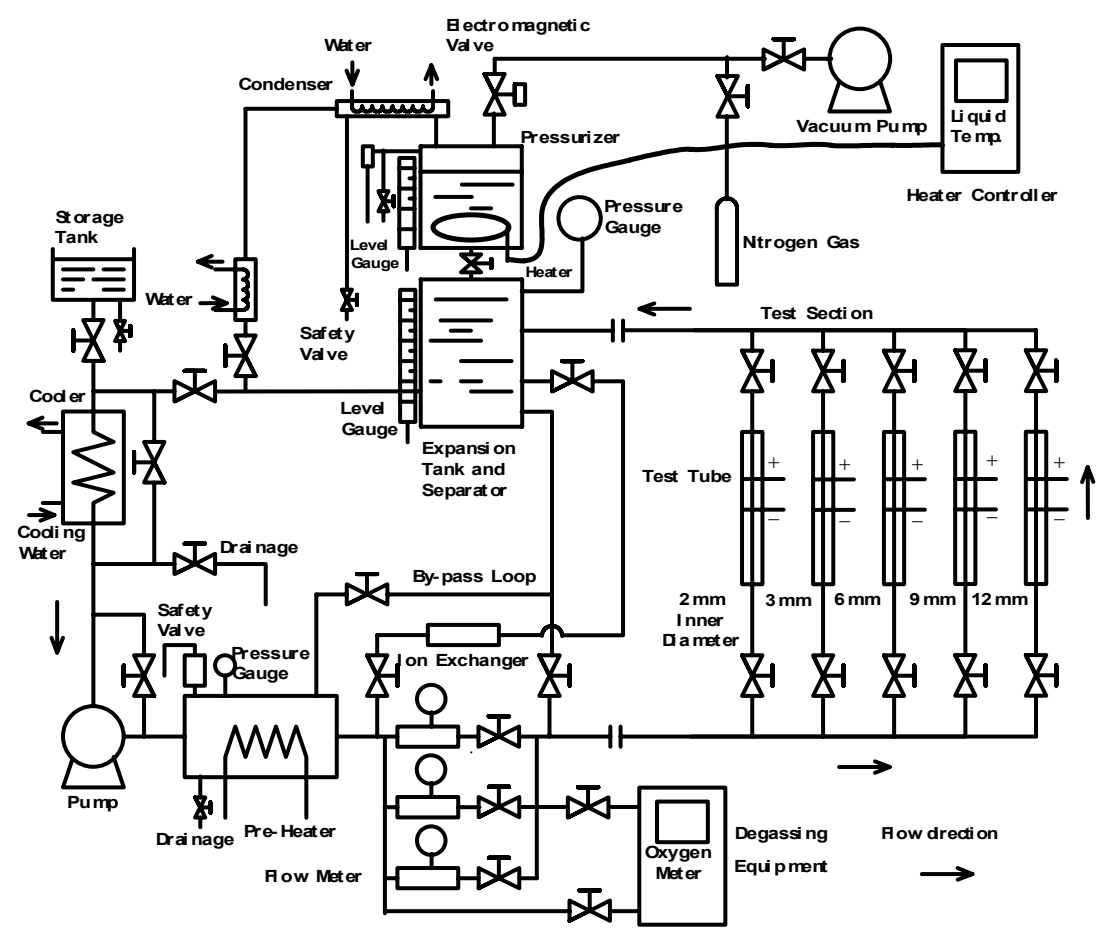

Figure 1 Schematic diagram of experimental water loop.

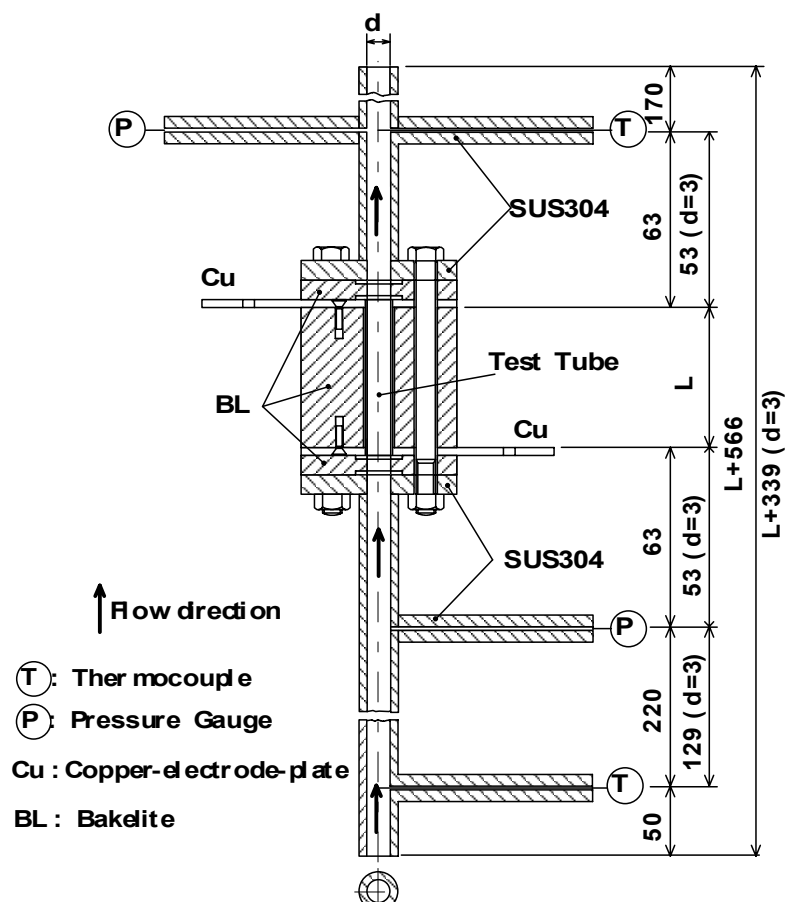

Figure 2 Vertical cross-sectional view of 3, 6 and 9-mm inner diameter test sections. 


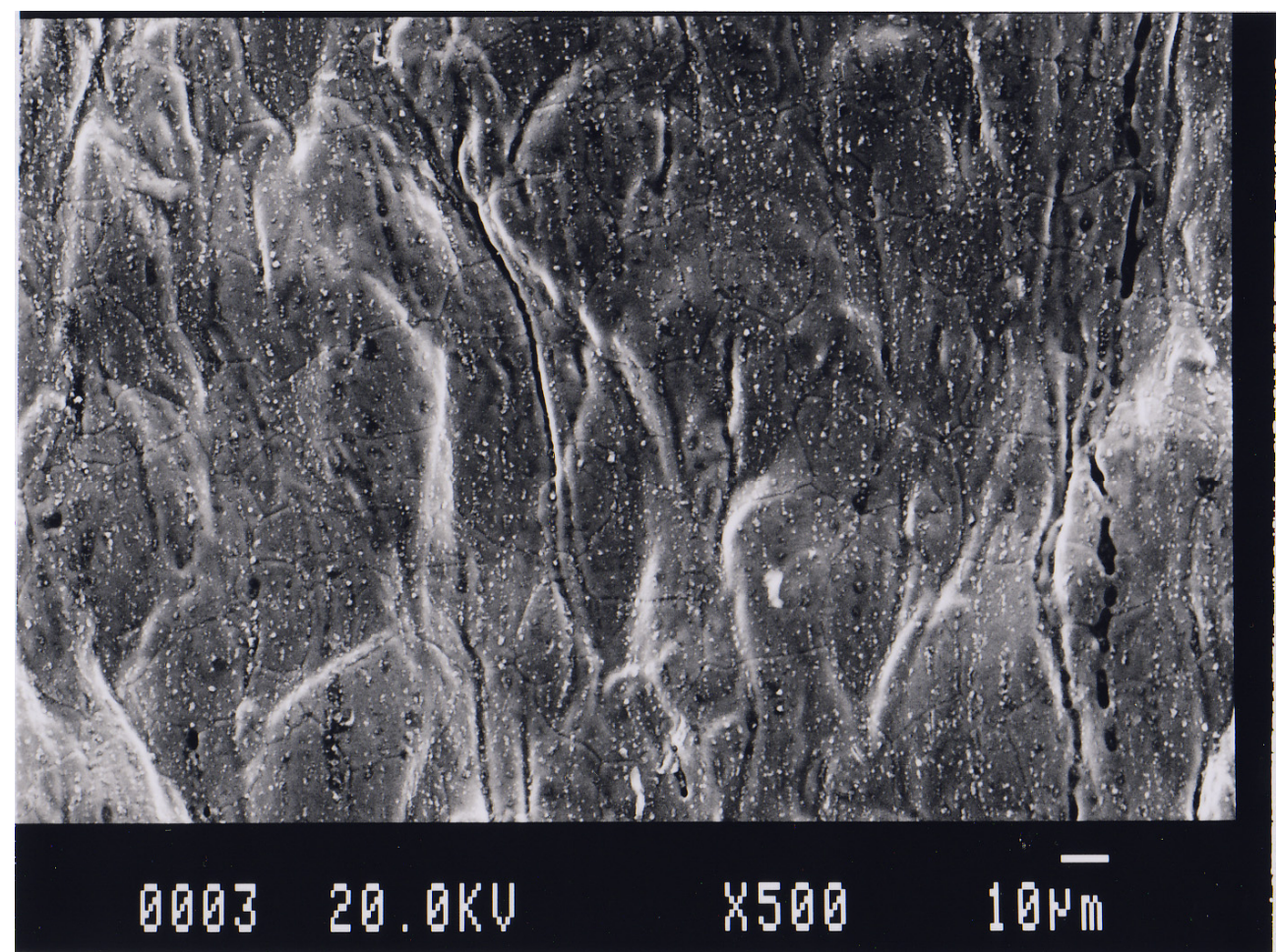

Figure 3 SEM photograph of the test tube with the rough finished inner surface.

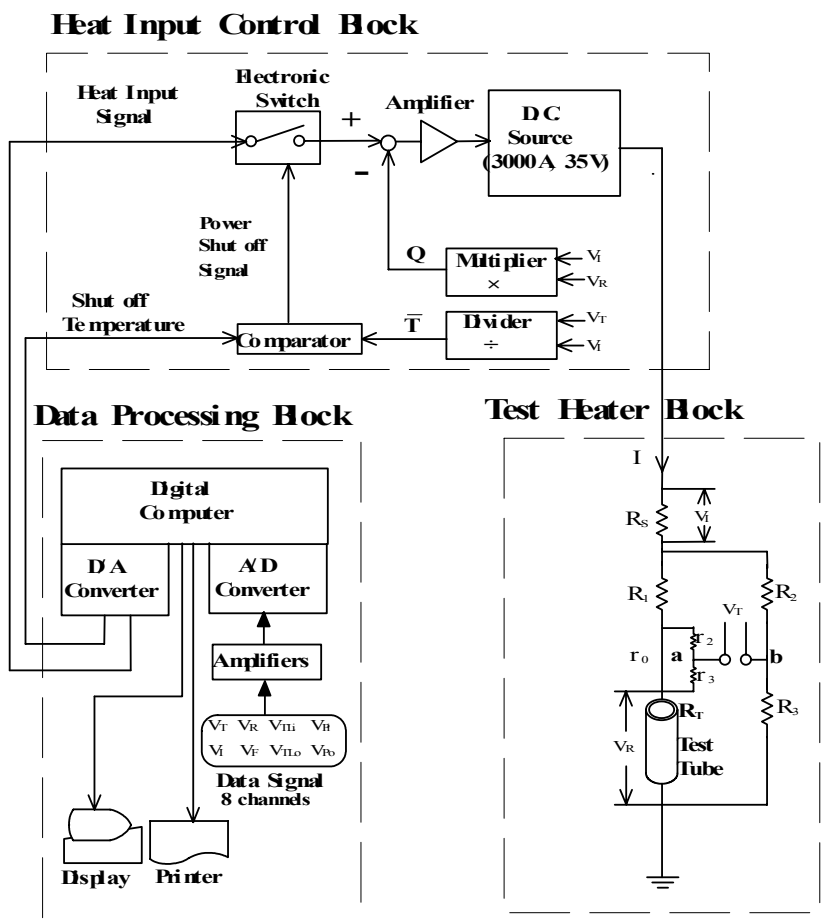

Figure 4 Measurement and data processing system. 


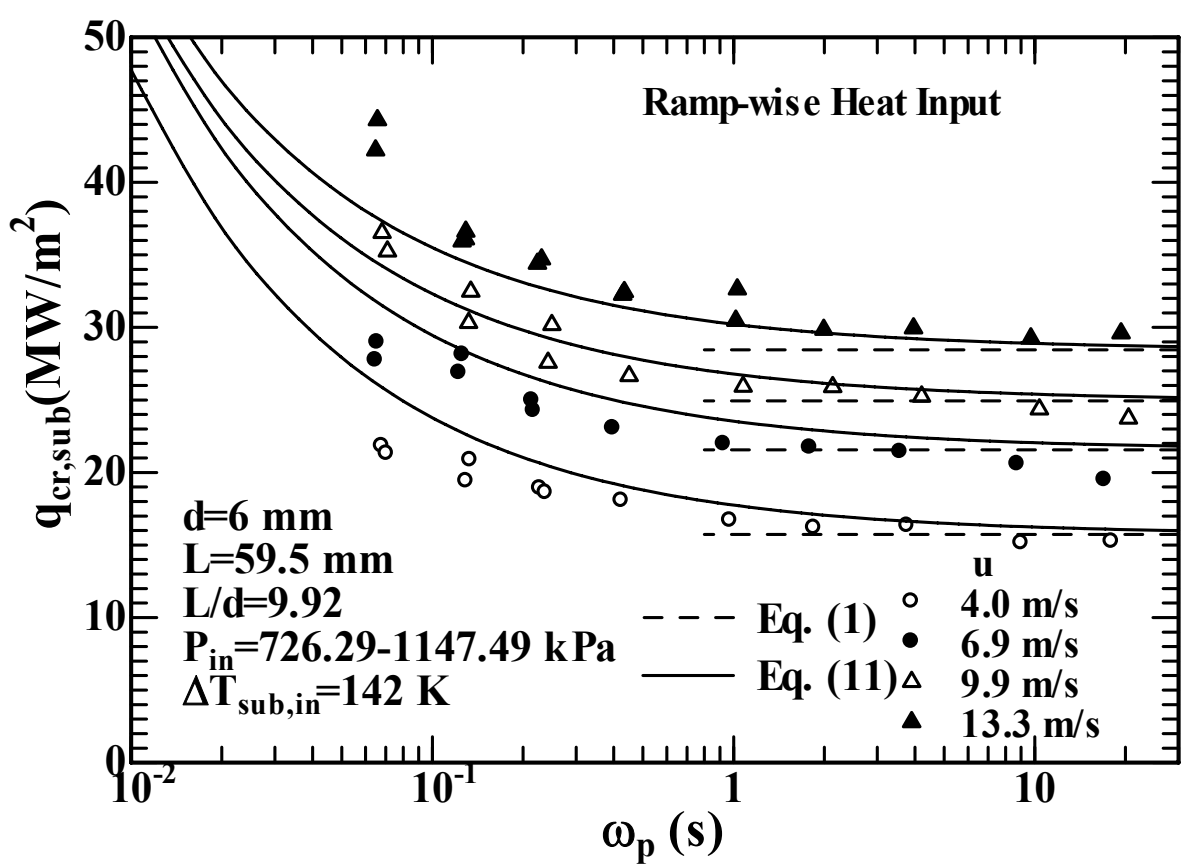

Figure 5 The $q_{c r, s u b}$ for $d=6 \mathrm{~mm}$ with ramp-wise heat input at $\Delta T_{s u b, i n}=142 \mathrm{~K}$ for $\omega_{p}=0.0656$ to $20.5 \mathrm{~s}$.

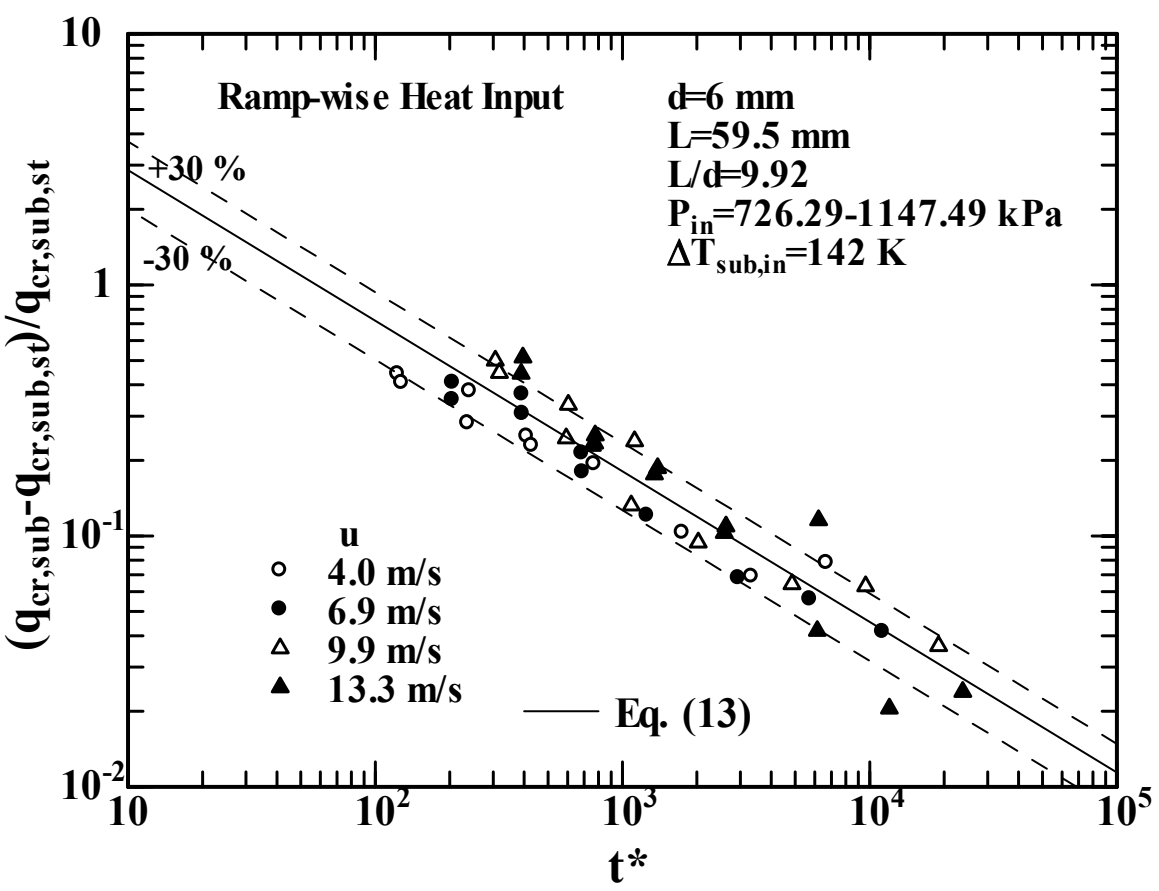

Figure $6\left(q_{c r, s u b}-q_{c r, s u b, s t}\right) / q_{c r, s u b, s t}$ versus $t^{*}$ for $d=6 \mathrm{~mm}$ with ramp-wise heat input. 


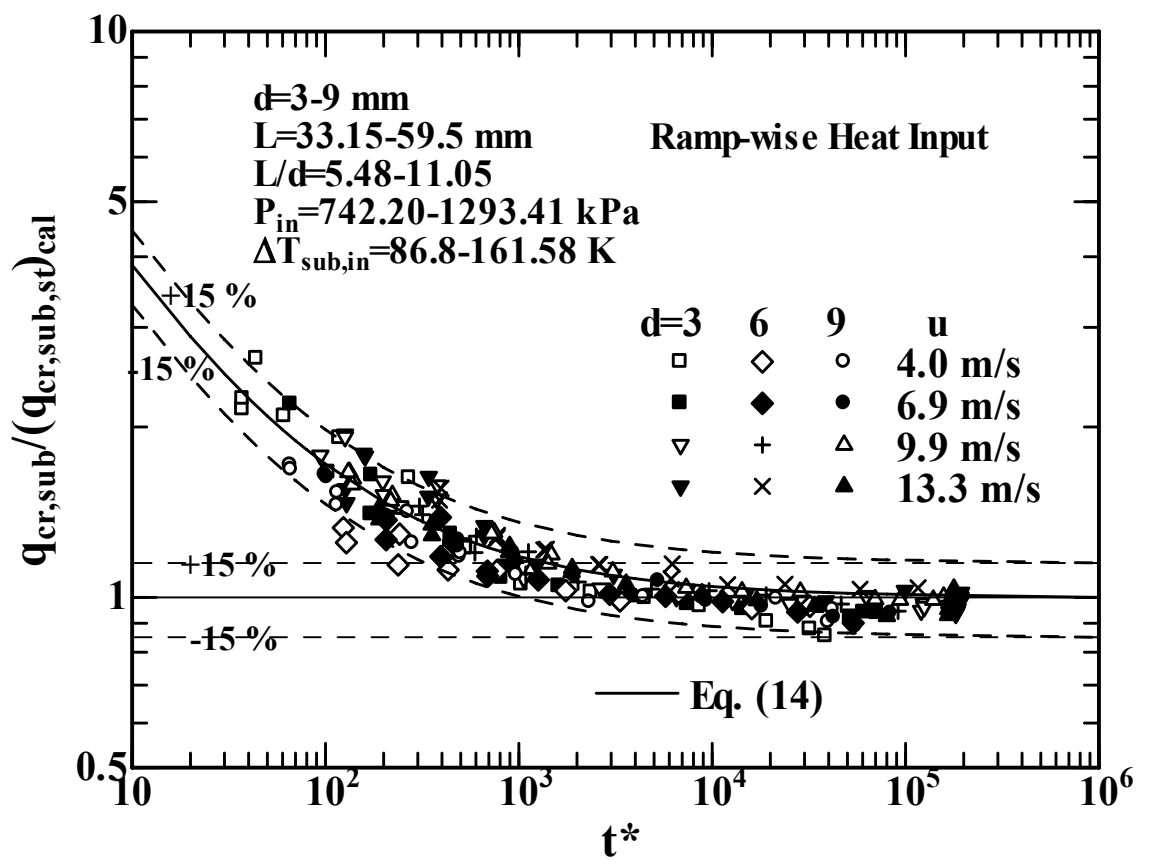

Figure 7 Ratios of $q_{c r, s u b}$ for $d=3$ to $9 \mathrm{~mm}$ with ramp-wise heat input (208 points) to calculated values by Eq. (1) versus $t^{*}$.

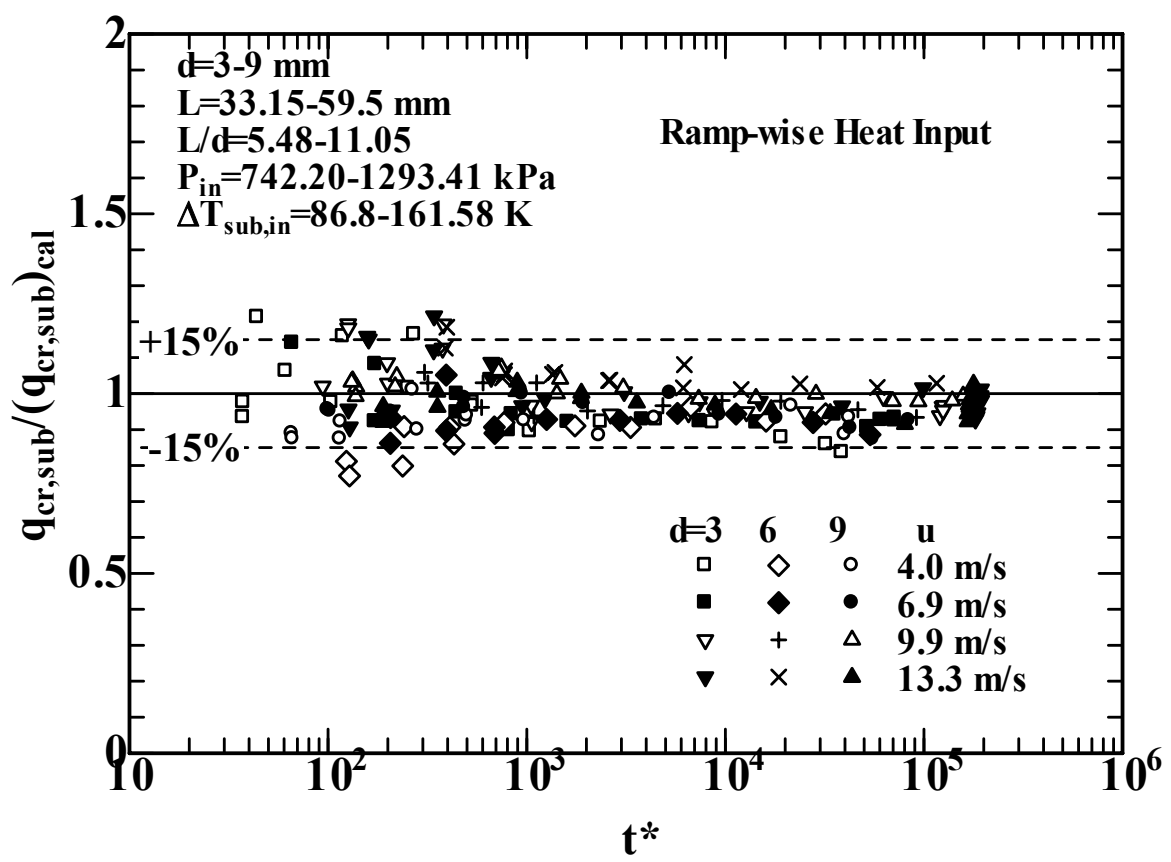

Figure 8 Ratios of $q_{c r, s u b}$ for $d=3$ to $9 \mathrm{~mm}$ with ramp-wise heat input (208 points) to calculated values by Eq. (14) versus $t^{*}$. 


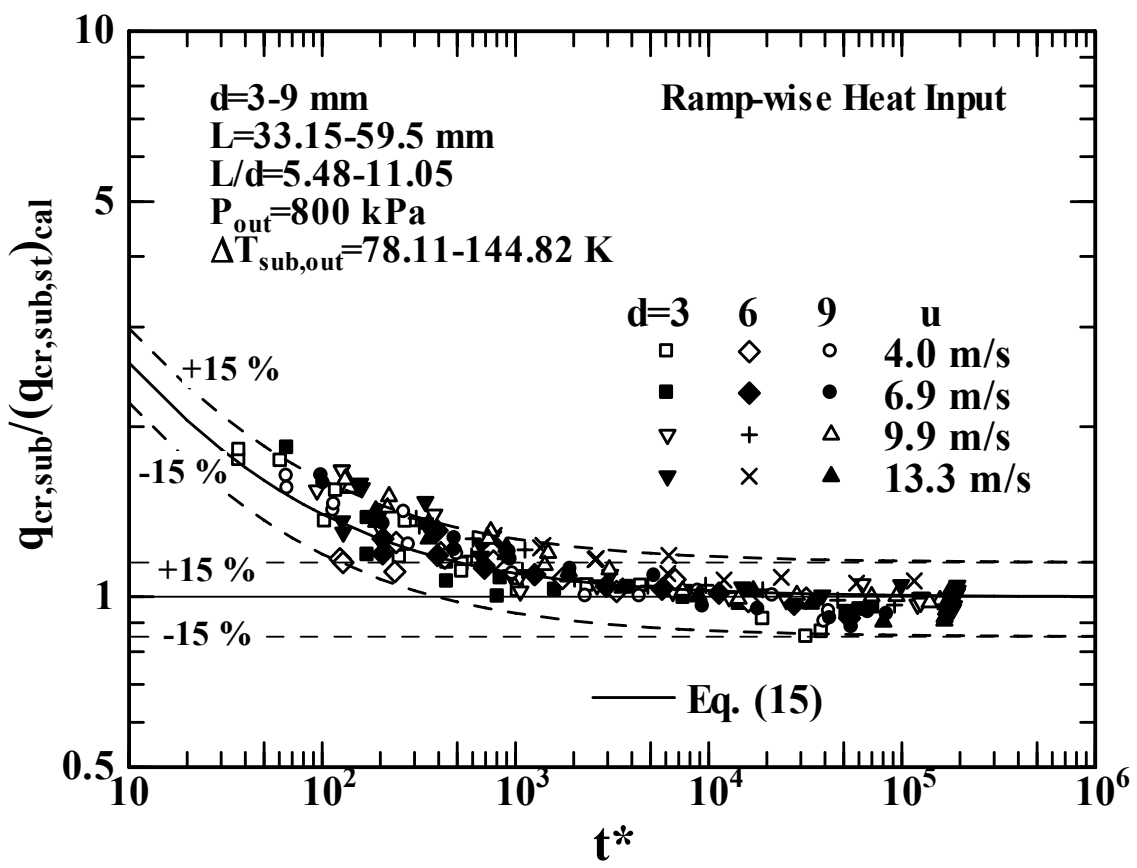

Figure 9 Ratios of $q_{c r, s u b}$ for $d=3$ to $9 \mathrm{~mm}$ with ramp-wise heat input (208 points) to calculated values by Eq. (2) versus $t^{*}$.

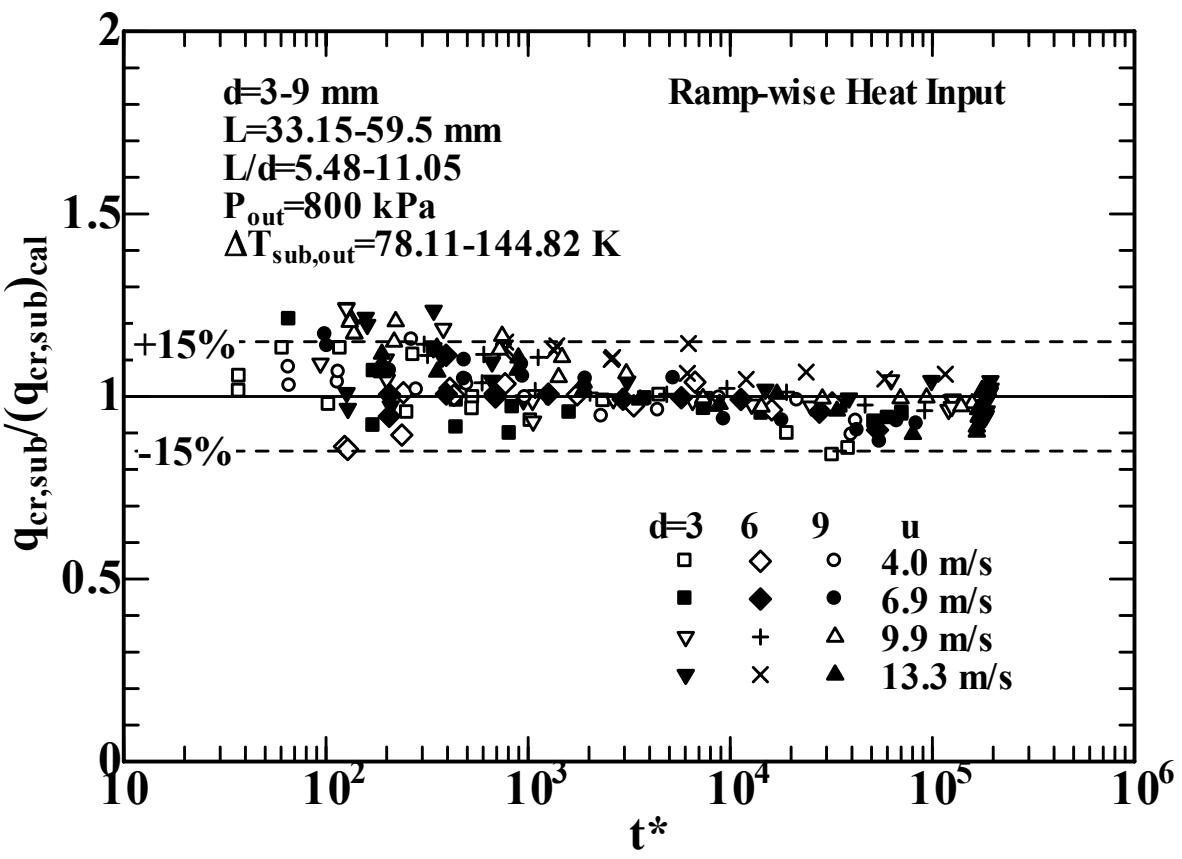

Figure 10 Ratios of $q_{c r, s u b}$ for $d=3$ to $9 \mathrm{~mm}$ with ramp-wise heat input (208 points) to calculated values by Eq. (15) versus $t^{*}$. 


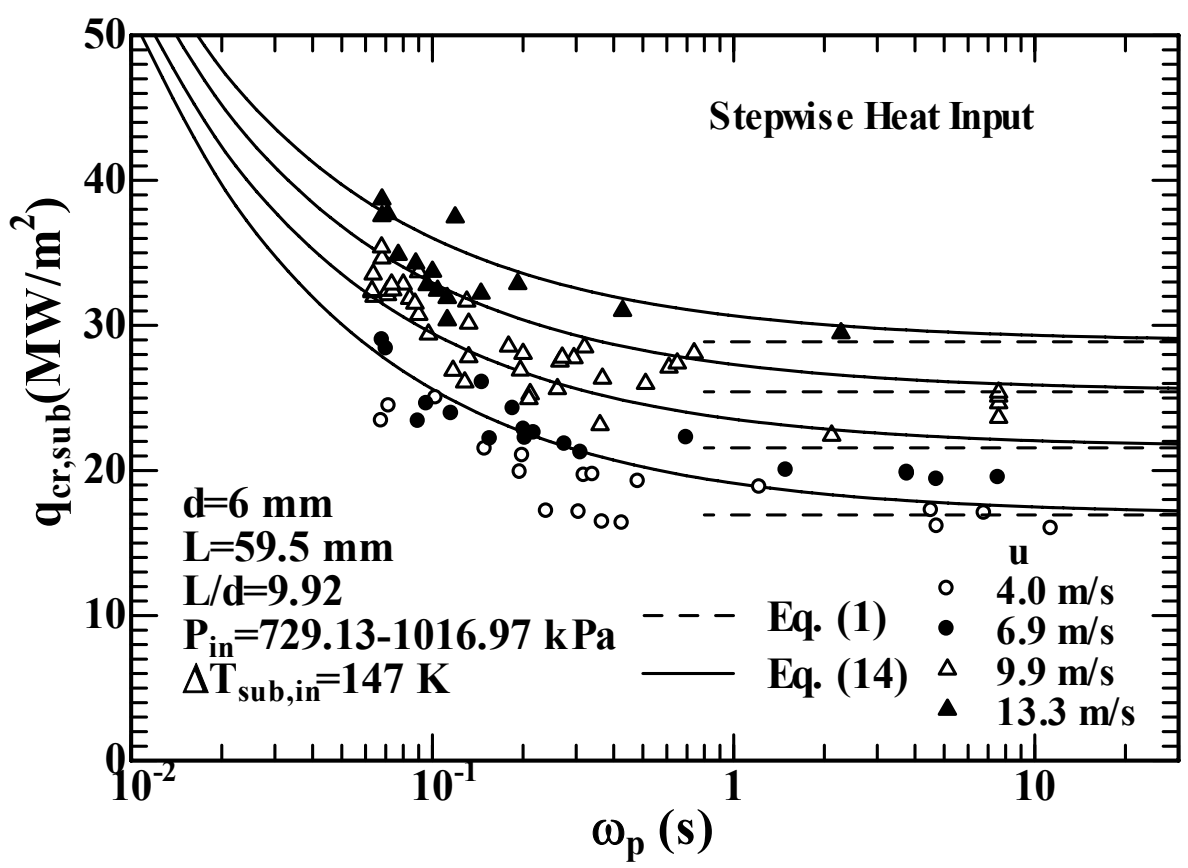

Figure 11 The $q_{c r, s u b}$ for $d=6 \mathrm{~mm}$ with stepwise heat input at $\Delta T_{\text {sub,in }}=$ $147 \mathrm{~K}$ for $\omega_{p}=\mathbf{0 . 0 6 3}$ to $11.4 \mathrm{~s}$.

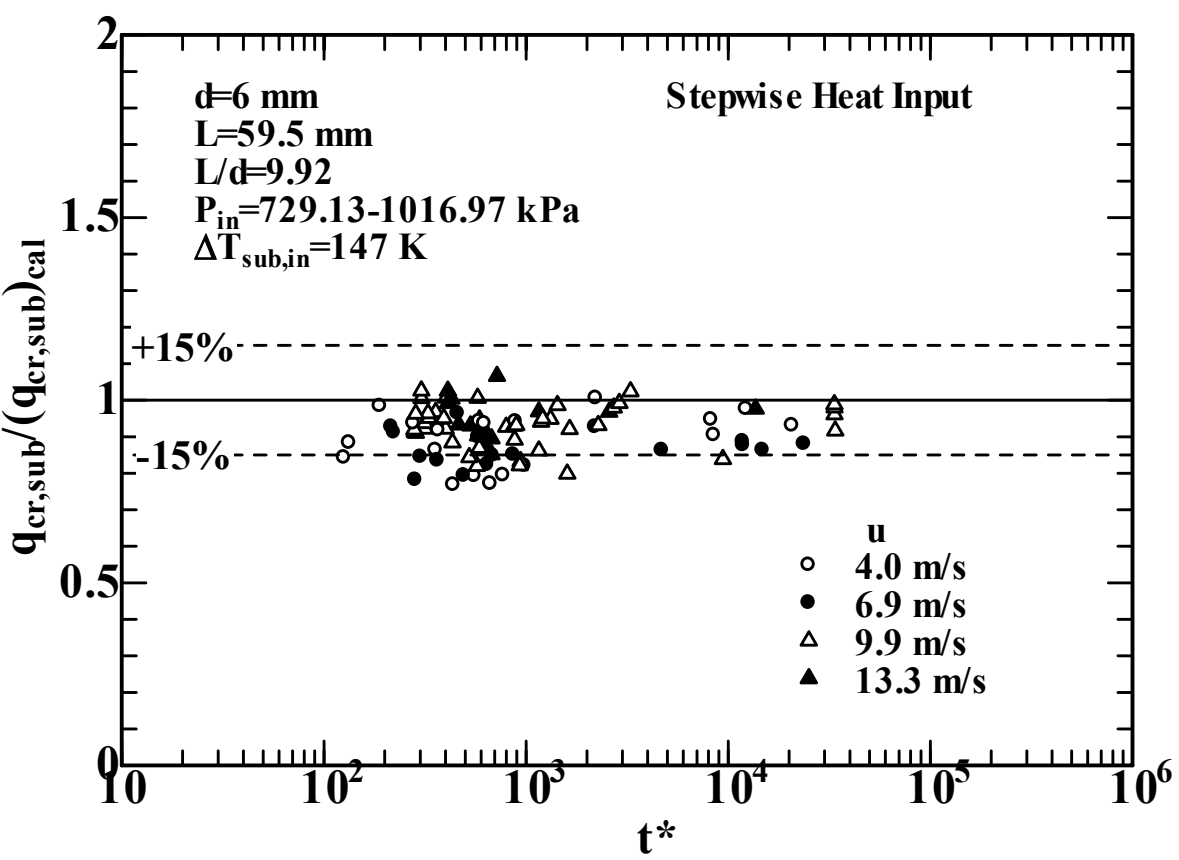

Figure 12 Ratios of $q_{c r, s u b}$ for $d=6 \mathrm{~mm}$ with stepwise heat input (105 points) to calculated values by Eq. (14) versus $t^{*}$. 


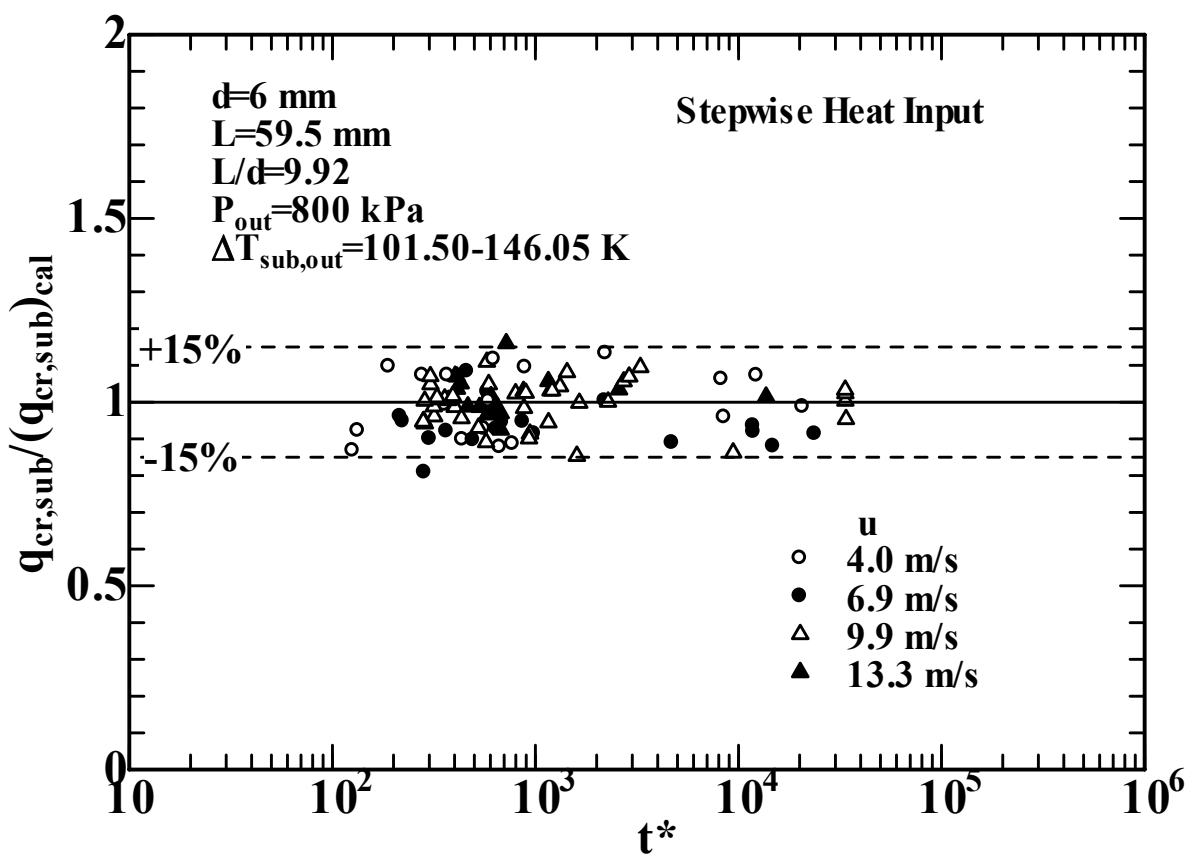

Figure 13 Ratios of $q_{c r, s u b}$ for $d=6 \mathbf{~ m m}$ with stepwise heat input (105 points) to calculated values by Eq. (15) versus $t$ *

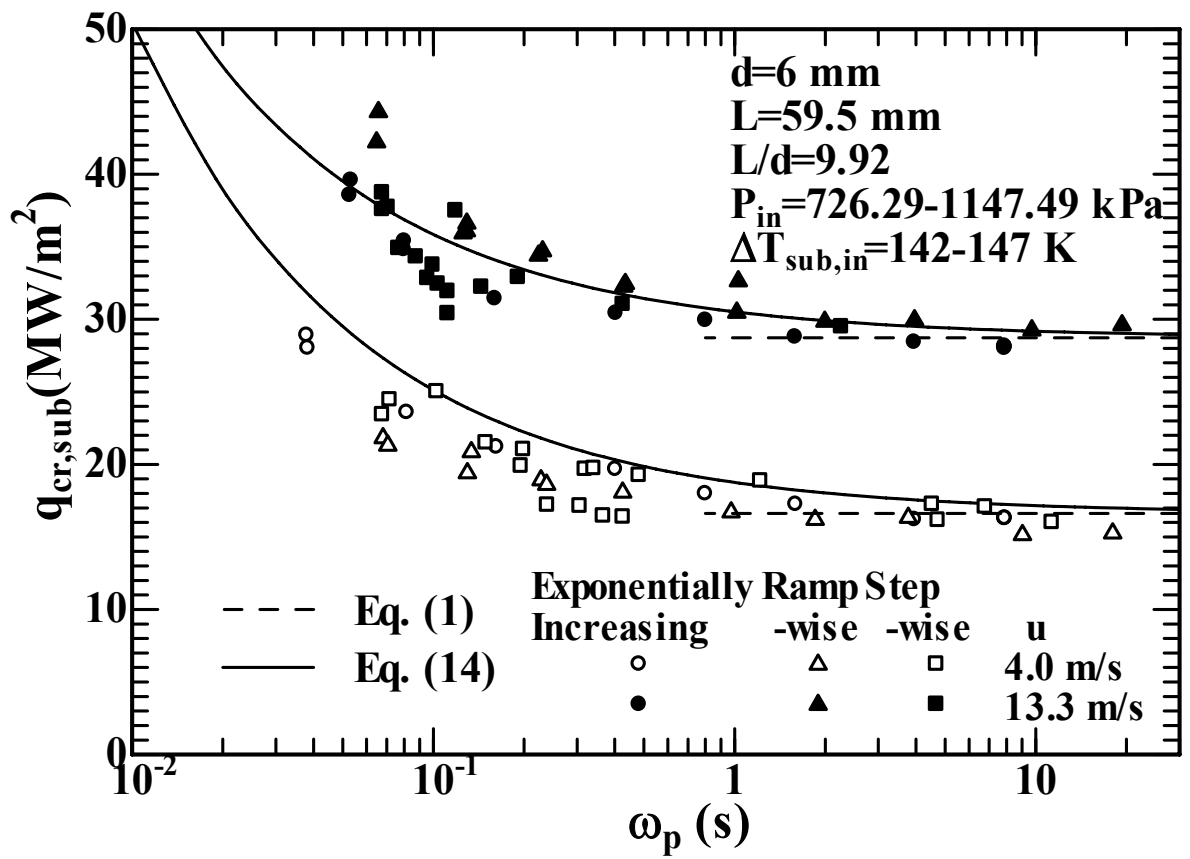

Figure 14 The $q_{c r, s u b}$ for various heat input waveforms with $\omega_{p}=0.038$ to $20.5 \mathrm{~s}$ at $u=4.0$ and $13.3 \mathrm{~m} / \mathrm{s}$. 


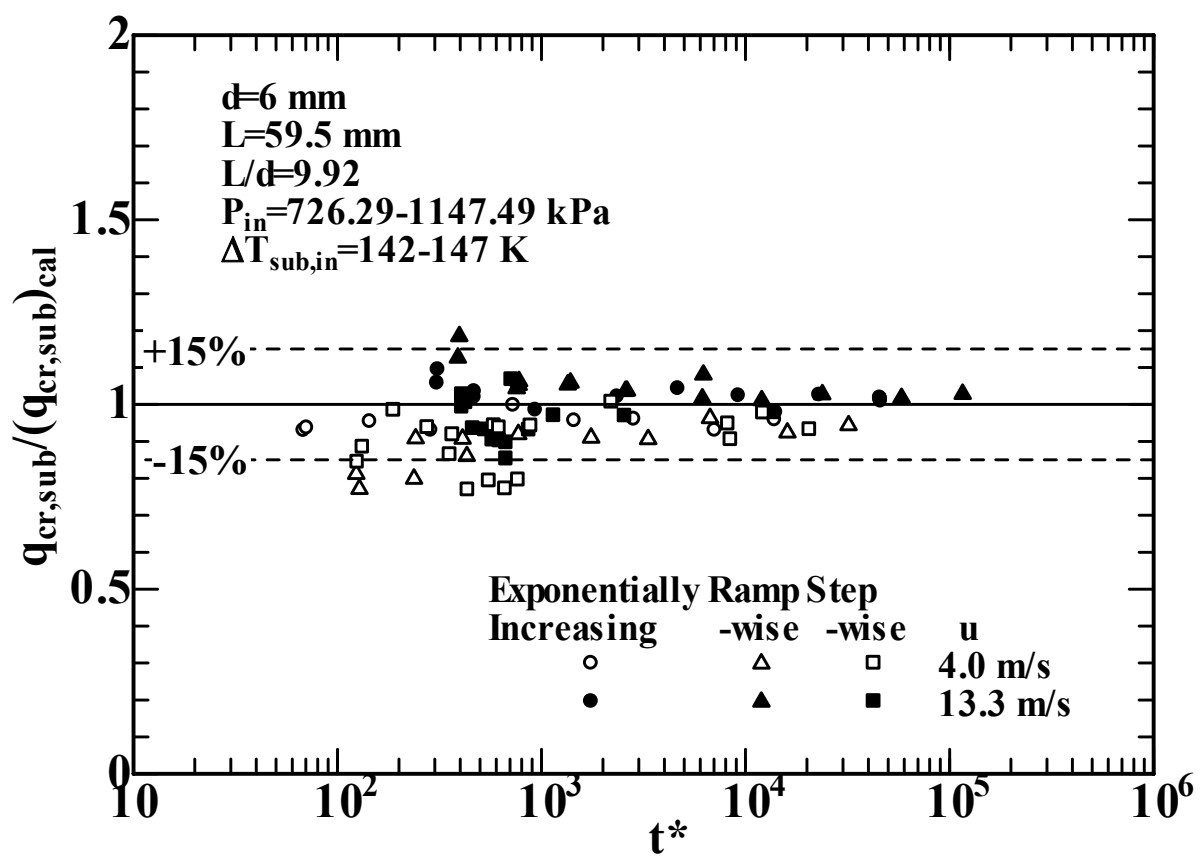

Figure 15 Ratios of $q_{c r, s u b}$ for various heat input waveforms to calculated values by Eq. (14) versus $t$ *.

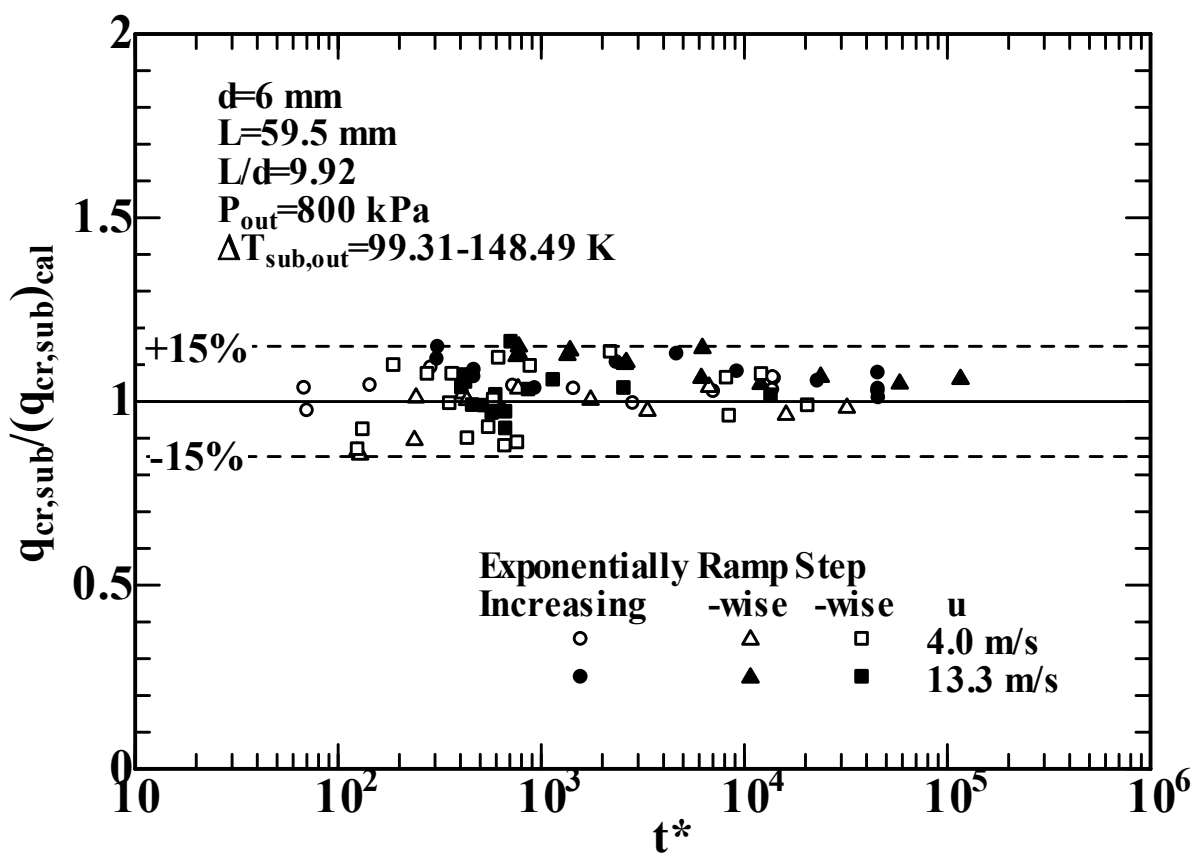

Figure 16 Ratios of $q_{c r, s u b}$ for various heat input waveforms to calculated values by Eq. (15) versus $t$ *. 


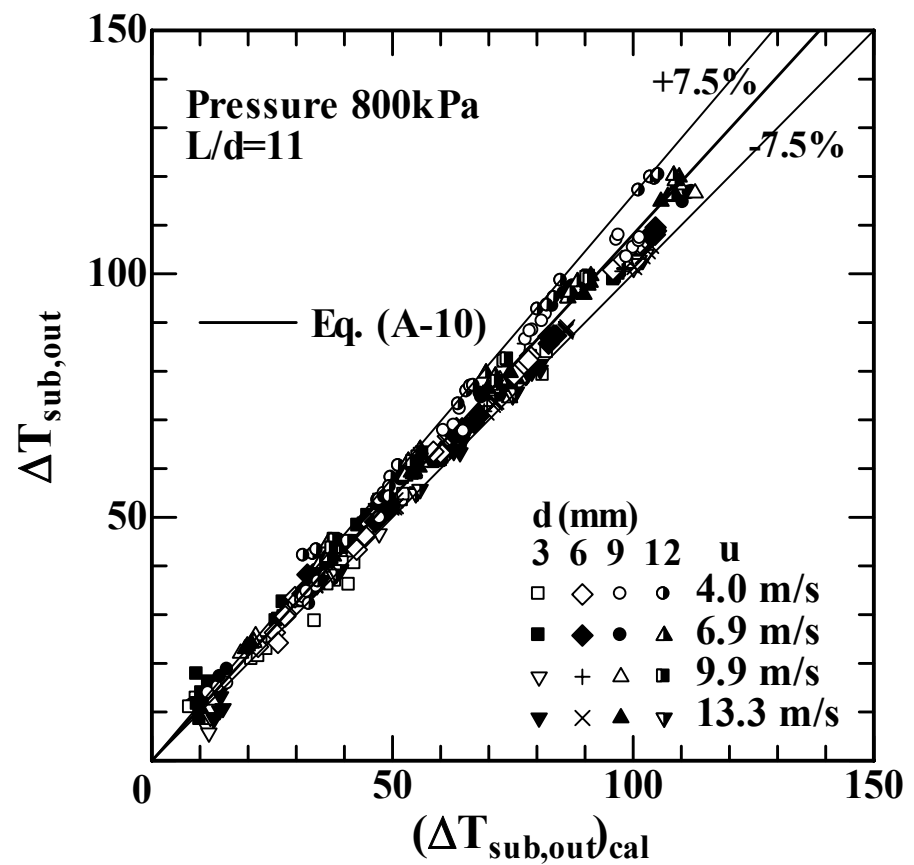

Figure a.1 Relationship between measured outlet subcooling and calculated outlet subcooling for the inner diameter of $3,6,9$ and 12 mm with $L / d=11$.

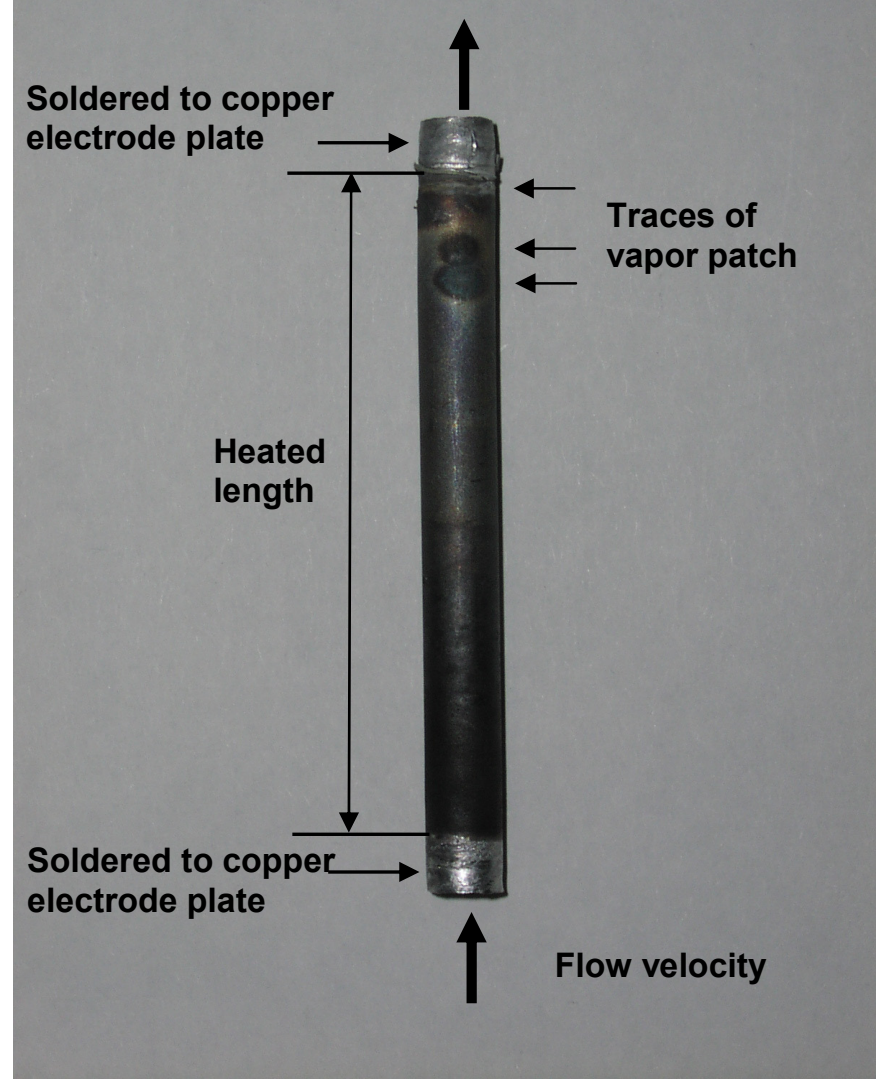

Figure a.2 Typical photograph of the test tube burned out. 


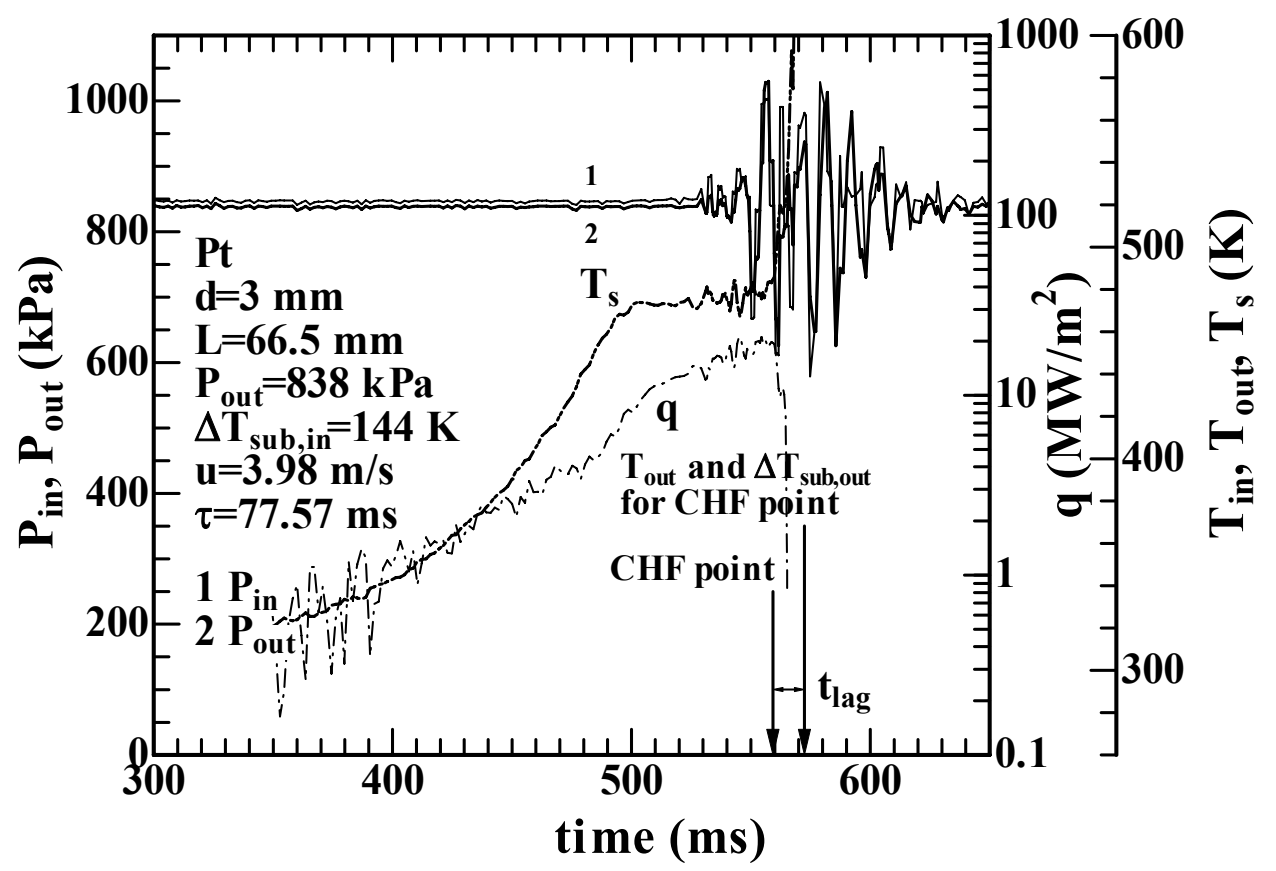

Figure a.3 Time variations in $P_{\text {in }}, P_{\text {out }}, q$ and $T_{s}$ for $P_{\text {out }}=838 \mathrm{kPa}$, $\Delta T_{\text {sub,in }}=144 \mathrm{~K}, u=3.98 \mathrm{~m} / \mathrm{s}$ and $\tau=77.57 \mathrm{~ms}$.

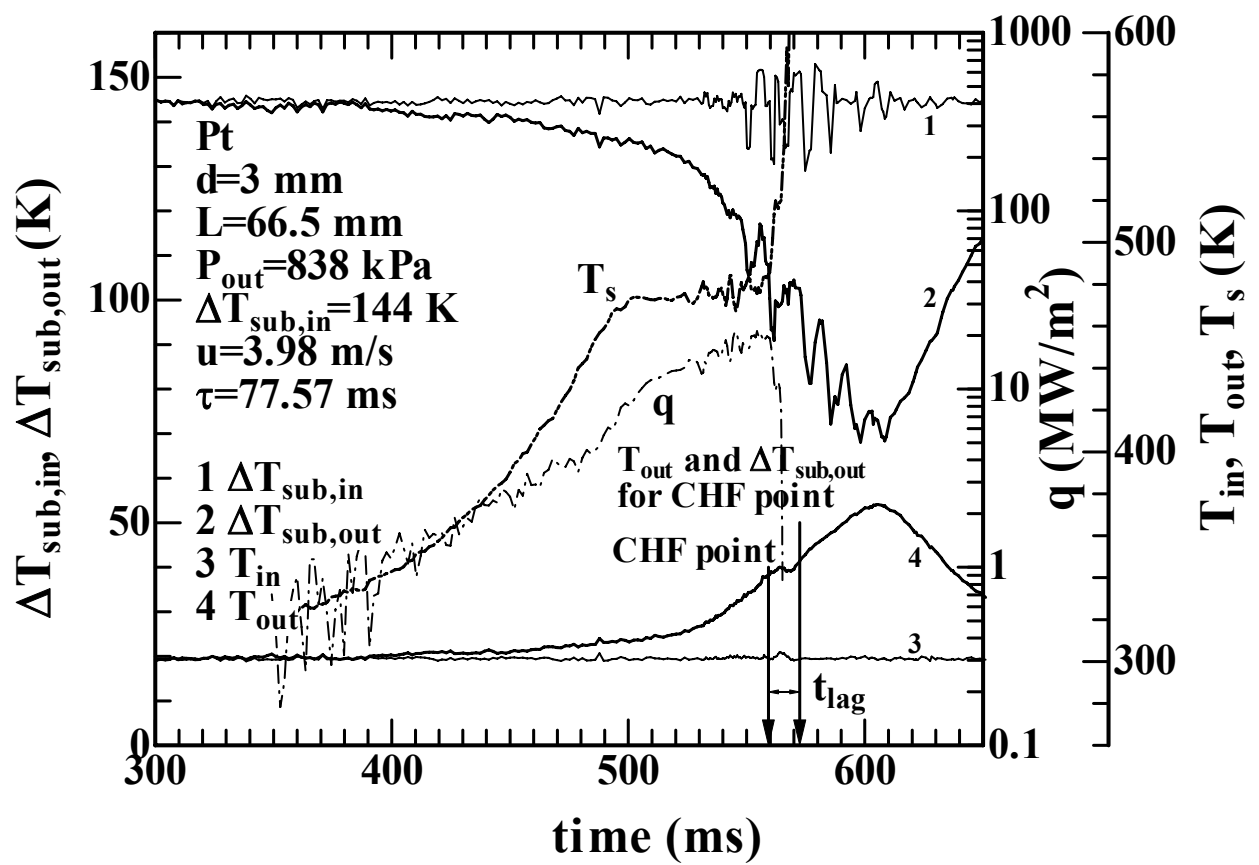

Figure a.4 Time variations in $T_{\text {in }}, T_{\text {out }}, \Delta T_{\text {sub,in }}, \Delta T_{\text {sub,out }}, q$ and $T_{s}$ for $P_{\text {out }}=838 \mathrm{kPa}, \Delta T_{\text {sub,in }}=144 \mathrm{~K}, u=3.98 \mathrm{~m} / \mathrm{s}$ and $\tau=77.57 \mathrm{~ms}$. 


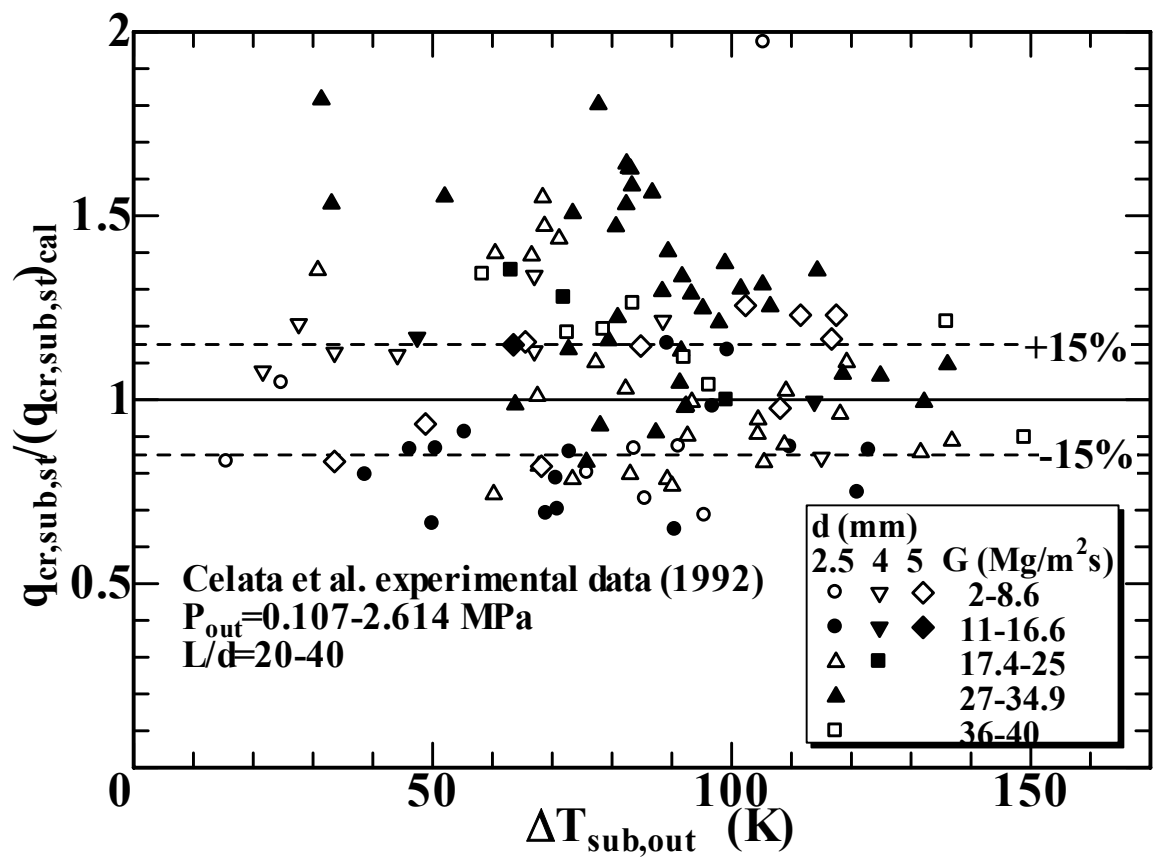

Figure a.5 Comparison of the values derived from the steady state CHF correlation against outlet subcooling, Eq. (2), with Celata et al. experimental data $[3]$.

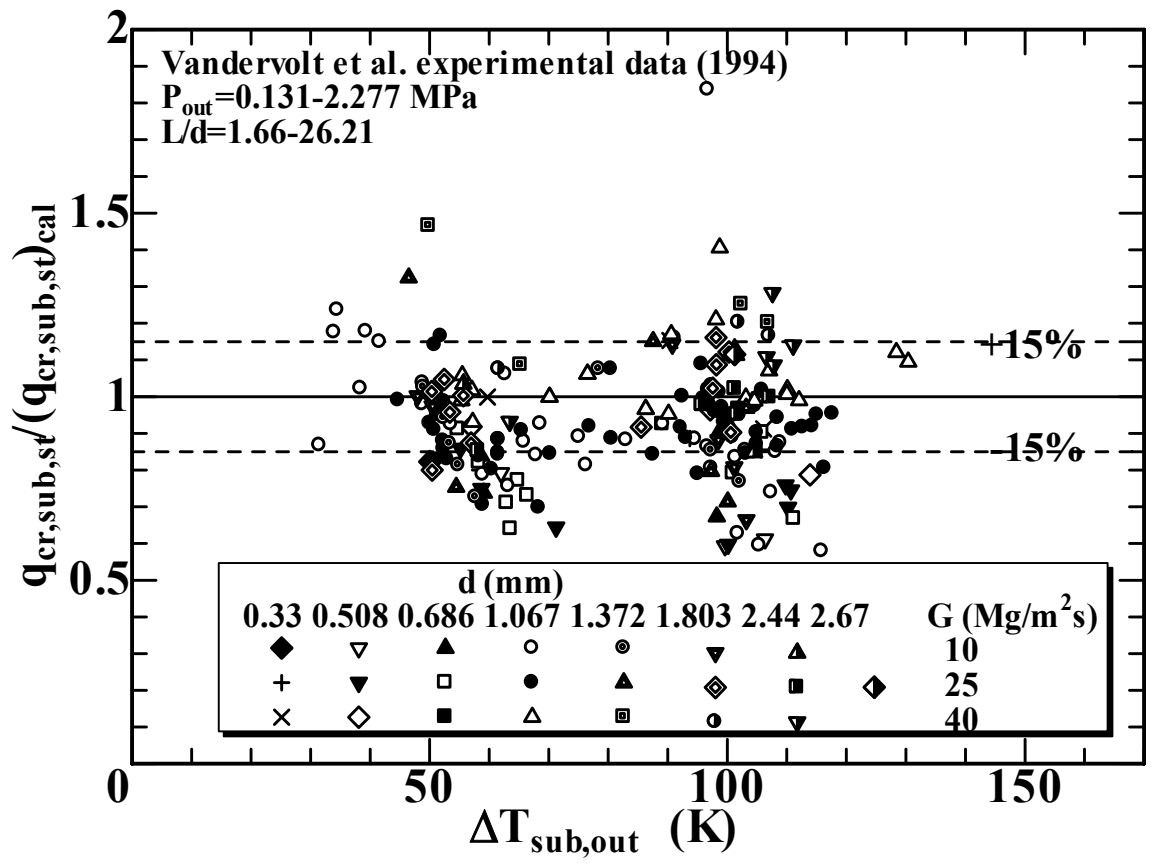

Figure a.6 Comparison of the values derived from the steady state CHF correlation against outlet subcooling, Eq. (2), with Vandervolt et al. experimental data [5]. 


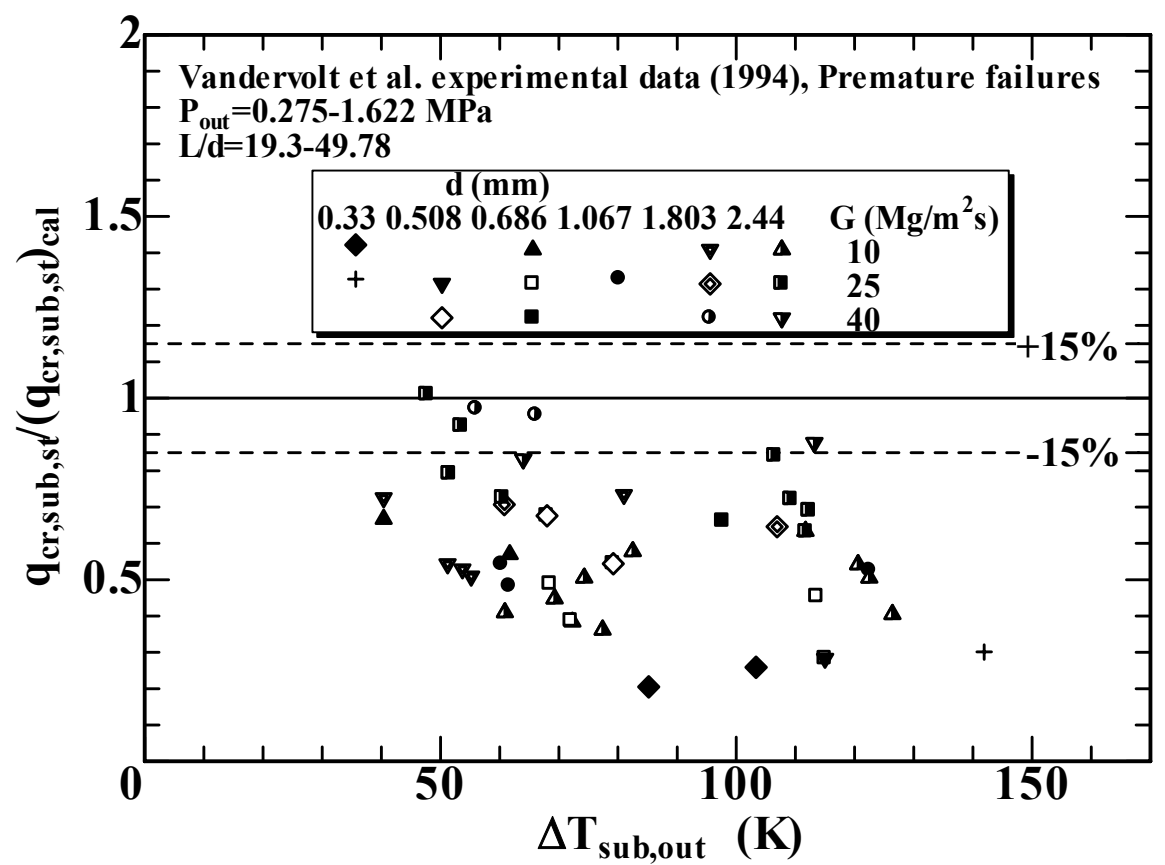

Figure a.7 Comparison of the values derived from the steady state CHF correlation against outlet subcooling, Eq. (2), with Vandervolt et al. experimental data [5], Premature failures.

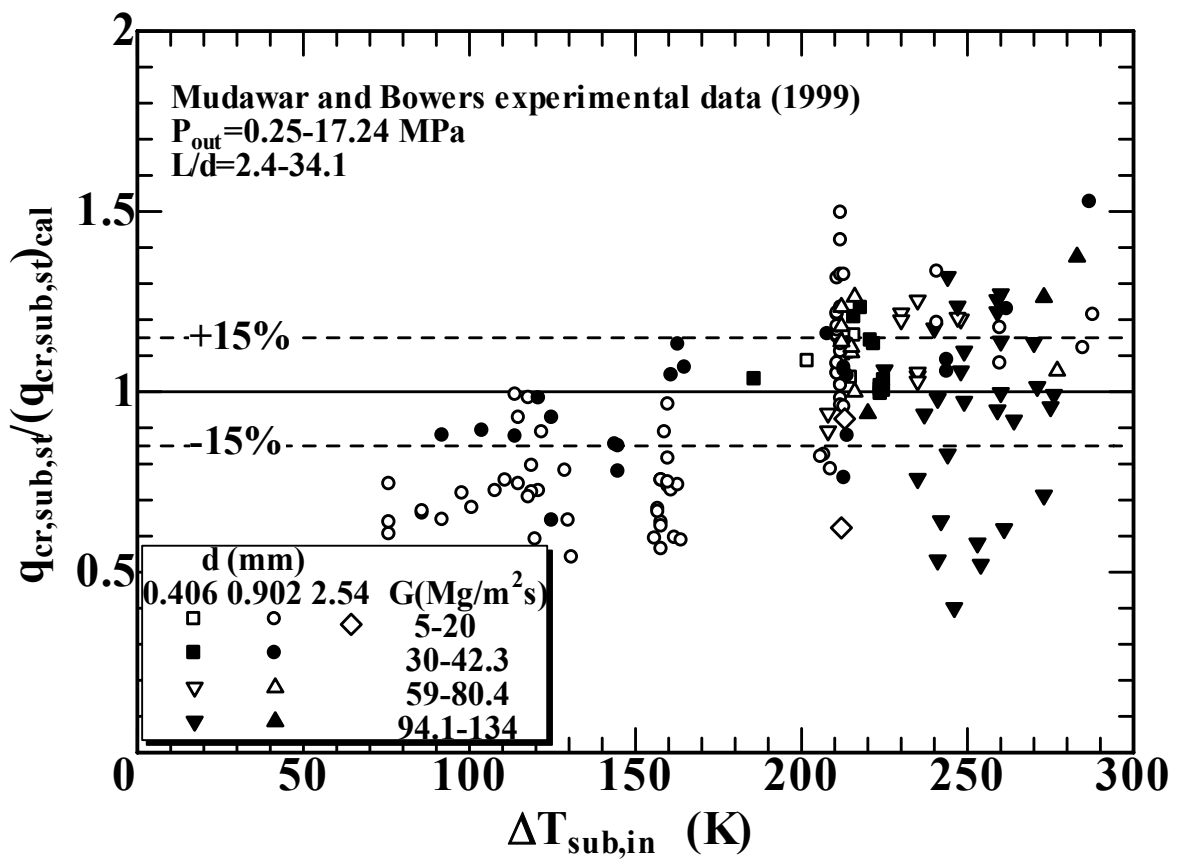

Figure a.8 Comparison of the values derived from the steady state CHF correlation against inlet subcooling, Eq. (1), with Mudawar and Bowers experimental data [7]. 


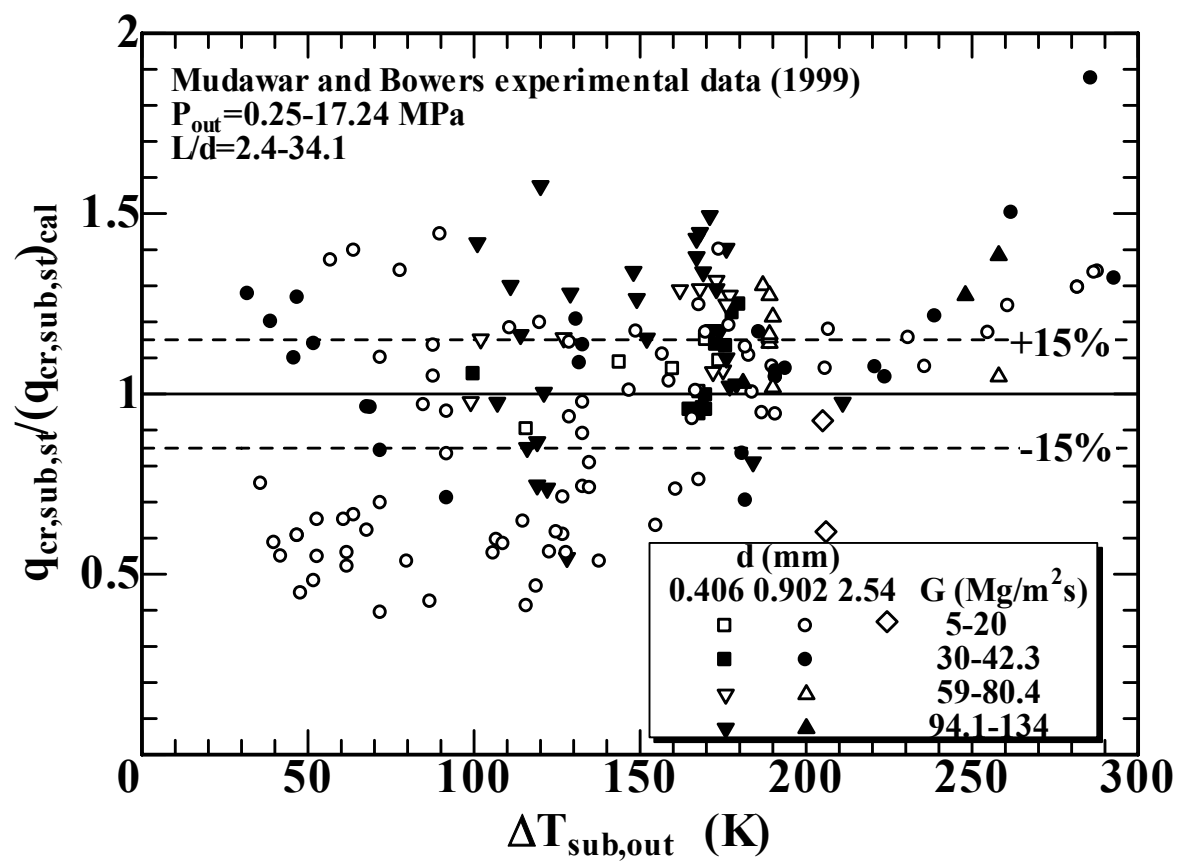

Figure a.9 Comparison of the values derived from the steady state CHF correlation against outlet subcooling, Eq. (2), with Mudawar and Bowers experimental data [7]. 